Supporting Information

\title{
Oxidative C-H/C-H Annulation of Imidazopyridines and Indazoles through Rhodium-Catalyzed Vinylene Transfer
}

Koushik Ghosh, ${ }^{\dagger}$ Yuji Nishii, ${ }^{*, \downarrow}$ and Masahiro Miura*,†

\footnotetext{
${ }^{\dagger}$ Department of Applied Chemistry, Graduate School of Engineering, Osaka University, Suita, Osaka 565-0871, Japan ‡Frontier Research Base for Global Young Researchers, Graduate School of Engineering, Osaka University, Suita, Osaka 565-0871, Japan
}

*y_nishii@chem.eng.osaka-u.ac.jp.

*miura@chem.eng.osaka-u.ac.jp.

\section{Contents}

1. General information $\quad$ S2

2. Experimental procedures and identification data S3

3. X-ray crystallographic analysis $\quad \mathrm{S} 12$

4. Copy of NMR spectra $\quad$ S16

5. Cartesian coordinates of the optimized structures $\quad$ S42

6. References $\quad$ S45 


\section{General information}

1,4-Dioxane and MeCN were dried and deoxygenated by a Glass Counter Solvent Dispending System (Nikko Hansen \& Co., Ltd.). Dichloroethane (DCE) and dimethylsulfoxide (DMSO) were distilled over $\mathrm{CaH}_{2}$ and stored with activated molecular sieves $4 \mathrm{~A}$. THF and ethanol were purchased as the dehydrated solvent and used as received. 2-Arylimidazo[1,2- $a$ ]-pyridines (1a-1r), 2-aryl-2 $H$-indazoles (4a-4d), 2-arylpyrazolo[1,5- $a]$ pyridines (5a-5d), and methyl 2-phenylpyrazolo[1,5-a]pyridine-3-carboxylate (8) were prepared according to the literature procedures. ${ }^{1}\left[\mathrm{Cp} * \mathrm{Rh}(\mathrm{MeCN})_{3}\right]\left[\mathrm{SbF}_{6}\right]_{2}$ and $\left[\mathrm{Cp}^{*} \mathrm{RhCl}_{2}\right]_{2}$ were prepared according to the literature procedures. ${ }^{2}$ All other reagents were purchased from commercial suppliers and used without further purification.

NMR spectra were recorded on Bruker AVANCE III 400 spectrometer operating at $400 \mathrm{MHz}\left({ }^{1} \mathrm{H}\right.$ NMR), at 100 $\mathrm{MHz}\left({ }^{13} \mathrm{C} \mathrm{NMR}\right)$, and at $376 \mathrm{MHz}\left({ }^{19} \mathrm{~F} \mathrm{NMR}\right)$. The chemical shifts were reported in parts per million relative to the resonance of internal standard TMS $(0.00 \mathrm{ppm})$ or the residual solvent signals for $\mathrm{CDCl}_{3}\left(7.26 \mathrm{ppm}\right.$ for ${ }^{1} \mathrm{H}$ NMR, 77.0 ppm for ${ }^{13} \mathrm{C}$ NMR). The peak patterns are indicated as follows: $\mathrm{s}$, singlet; $\mathrm{d}$, doublet; $\mathrm{t}$, triplet; $\mathrm{m}$, multiplet; q, quartet; sept, septet. The coupling constants are reported in Hertz (Hz). High resolution mass spectra (HRMS) were recorded on Bruker micrOTOF II-H3 by APCI-TOF. Melting points were measured with Mettler Toledo MP90. Silica gel column chromatography was performed using Wakosil ${ }^{\circledR} \mathrm{C}-200(64-210 \mu \mathrm{m})$. Preparative gel permeation chromatography (GPC) was conducted with Showa Denko H-2001, H-2002 column (eluent: $\mathrm{CHCl}_{3}$ ) or YMC T2000 (eluent: EtOAc) column. Absorption and fluorescence spectra were recorded with JASCO V-750 spectrometer. Photoluminescence spectra were recorded with JASCO FP-8500 spectrometer. Quantum yield was determined using an integration sphere system. All calculations were carried out using the Gaussian 09 program. The DFT calculations were carried out using the B3LYP function with 6$31 \mathrm{G}(\mathrm{d})$ basis set for all atoms. The optimized molecular structures were verified by vibrational analysis; equilibrium structures had no imaginary frequencies. 


\section{Experimental procedures and identification data}

\section{2-1. Rh-catalyzed annulative coupling with vinylene carbonate (Scheme 2 and Scheme 6)}

To an oven dried screw-top tube were placed an 2-arylimidazo[1,2-a]-pyridine (1) / 2-aryl-2 $H$-indazole (4) / 2-arylpyrazolo[1,5-a]pyridines (5) / methyl 2-phenylpyrazolo[1,5-a]pyridine-3-carboxylate (8) (0.3 mmol, 1.0 equiv) and $\left[\mathrm{Cp}^{*} \mathrm{Rh}(\mathrm{MeCN})_{3}\right]\left[\mathrm{SbF}_{6}\right]_{2}(6.0 \mathrm{~mol} \%)$. DCE $(1.5 \mathrm{~mL})$ and vinylene carbonate $(0.6$ mmol, 2.0 equiv) were added via syringe. The mixture was heated with an oil bath at $120{ }^{\circ} \mathrm{C}$ for $24 \mathrm{~h}$. Volatiles were removed in vacuo, and the residue was purified by silica gel column chromatography.

\section{2-2. Rh-catalyzed annulative coupling in $1.0 \mathrm{mmol}$ scale (Scheme 3)}

To an oven dried screw-top tube were placed an 5-methyl-2-phenylimidazo[1,2-a]pyridine (1n) (1.0 mmol, 1.0 equiv) and $\left[\mathrm{Cp} * \mathrm{Rh}(\mathrm{MeCN})_{3}\right]\left[\mathrm{SbF}_{6}\right]_{2}(6.0 \mathrm{~mol} \%)$. DCE $(4.0 \mathrm{~mL})$ and vinylene carbonate $(2.0$ mmol, 2.0 equiv) were added via syringe. The mixture was heated with an oil bath at $120{ }^{\circ} \mathrm{C}$ for $24 \mathrm{~h}$. Volatiles were removed in vacuo, and the residue was purified by silica gel column chromatography (eluent: hexane/EtOAc $=1 / 1)$ to give $3 \mathrm{n}$ in $77 \%$ yield $(180 \mathrm{mg}$ ) as white solid.

Naphtho[ $\left[1^{\prime}, 2^{\prime}: 4,5\right]$ imidazo[ $[1,2-a]$ pyridine $(\mathbf{3 a})^{3}$

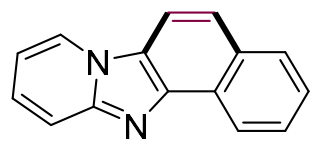

Purified by silica gel column chromatography (eluent: hexane/EtOAc $=1 / 1), 53 \mathrm{mg}(80 \%$ yield), white solid, mp 193-195 ${ }^{\circ} \mathrm{C} ;{ }^{1} \mathrm{H}$ NMR (400 MHz, $\left.\mathrm{CDCl}_{3}\right) \delta 8.80-8.86(\mathrm{~m}, 1 \mathrm{H}), 8.39$ (td, $\left.J=1.1,6.8 \mathrm{~Hz}, 1 \mathrm{H}\right)$, $7.97(\mathrm{~d}, J=8.0 \mathrm{~Hz}, 1 \mathrm{H}), 7.77-7.85(\mathrm{~m}, 2 \mathrm{H}), 7.64-7.73(\mathrm{~m}, 2 \mathrm{H}), 7.54-7.62(\mathrm{~m}, 1 \mathrm{H}), 7.32-7.40(\mathrm{~m}, 1 \mathrm{H})$, $6.85(\mathrm{dt}, J=1.1,6.8 \mathrm{~Hz}, 1 \mathrm{H}) ;{ }^{13} \mathrm{C} \mathrm{NMR}\left(100 \mathrm{MHz}, \mathrm{CDCl}_{3}\right) \delta 147.2,141.1,132.0,128.6,127.5,126.8$, 126.6, 125.9, 124.4, 124.2, 122.9, 122.4, 117.9, 111.2, 110.0; HRMS (APCI) $m / z$ calcd for $\mathrm{C}_{15} \mathrm{H}_{11} \mathrm{~N}_{2}{ }^{+}$ $\left([\mathrm{M}+\mathrm{H}]^{+}\right)$219.0917, found 219.0916.

3-Methylnaphtho[1',2':4,5]imidazo[1,2-a]pyridine (3b)

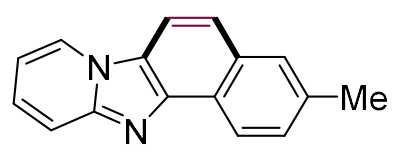

Purified by silica gel column chromatography (eluent: hexane/EtOAc $=1 / 1), 54 \mathrm{mg}(77 \%$ yield), white solid, mp 156-158 ${ }^{\circ} \mathrm{C} ;{ }^{1} \mathrm{H}$ NMR $\left(400 \mathrm{MHz}, \mathrm{CDCl}_{3}\right) \delta 8.71(\mathrm{~d}, J=8.0 \mathrm{~Hz}, 1 \mathrm{H}), 8.35$ (td, $J=1.1,6.8 \mathrm{~Hz}$, 1H), 7.71-7.83 (m, 3H), 7.50-7.60 (m, 2H), 7.30-7.37 (m, 1H), $6.82(\mathrm{dt}, J=1.1,6.8 \mathrm{~Hz}, 1 \mathrm{H}), 2.56(\mathrm{~s}, 3 \mathrm{H})$; ${ }^{13} \mathrm{C}$ NMR $\left(100 \mathrm{MHz}, \mathrm{CDCl}_{3}\right) \delta$ 147.2, 141.2, 135.6, 132.3, 128.6, 127.9, 127.3, 124.7, 124.3, 123.9, 122.8, 121.9, 117.8, 111.0, 110.0, 21.8; HRMS (APCI) $m / z$ calcd for $\mathrm{C}_{16} \mathrm{H}_{13} \mathrm{~N}_{2}{ }^{+}\left([\mathrm{M}+\mathrm{H}]^{+}\right)$233.1073, found 233.1073 . 
3-Methoxynaphtho[1',2':4,5]imidazo[1,2-a]pyridine (3c)

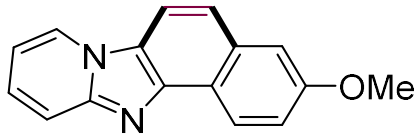

Purified by silica gel column chromatography (eluent: hexane/EtOAc $=1 / 1), 52 \mathrm{mg}(70 \%$ yield), white solid, mp 117-120 ${ }^{\circ} \mathrm{C} ;{ }^{1} \mathrm{H}$ NMR $\left(400 \mathrm{MHz}, \mathrm{CDCl}_{3}\right) \delta 8.73(\mathrm{~d}, J=8.8 \mathrm{~Hz}, 1 \mathrm{H}), 8.43(\mathrm{~d}, J=6.8 \mathrm{~Hz}, 1 \mathrm{H})$, 7.78-7.86 (m, 2H), $7.61(\mathrm{~d}, J=8.8 \mathrm{~Hz}, 1 \mathrm{H}), 7.31-7.41(\mathrm{~m}, 3 \mathrm{H}), 6.88(\mathrm{dt}, J=1.1,6.8 \mathrm{~Hz}, 1 \mathrm{H}), 3.96(\mathrm{~s}$, $3 \mathrm{H}) ;{ }^{13} \mathrm{C} \mathrm{NMR}\left(100 \mathrm{MHz}, \mathrm{CDCl}_{3}\right) \delta 157.9,147.3,141.5,133.4,127.4,124.5,124.3,123.3,121.5,121.4$, 117.9, 117.8, 111.0, 110.5, 108.0, 55.4; HRMS (APCI) $m / z$ calcd for $\mathrm{C}_{16} \mathrm{H}_{13} \mathrm{~N}_{2} \mathrm{O}^{+}\left([\mathrm{M}+\mathrm{H}]^{+}\right) 249.1022$, found 249.1022 .

3-Chloronaphtho[1',2':4,5]imidazo[1,2- $a]$ pyridine (3d)

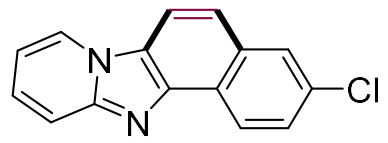

Purified by silica gel column chromatography (eluent: hexane/EtOAc $=1 / 1), 65 \mathrm{mg}(86 \%$ yield), white solid, mp 172-174 ${ }^{\circ} \mathrm{C} ;{ }^{1} \mathrm{H}$ NMR $\left(400 \mathrm{MHz}, \mathrm{CDCl}_{3}\right) \delta 8.65(\mathrm{~d}, J=8.8 \mathrm{~Hz}, 1 \mathrm{H}), 8.24(\mathrm{dt}, J=6.8,1.0 \mathrm{~Hz}$, $1 \mathrm{H}), 7.81(\mathrm{~d}, J=2.0 \mathrm{~Hz}, 1 \mathrm{H}), 7.70-7.76(\mathrm{~m}, 1 \mathrm{H}), 7.66(\mathrm{~d}, J=8.8 \mathrm{~Hz}, 1 \mathrm{H}), 7.56(\mathrm{dd}, J=2.0,8.8 \mathrm{~Hz}, 1 \mathrm{H})$, $7.40(\mathrm{~d}, J=8.8 \mathrm{~Hz}, 1 \mathrm{H}), 7.30-7.37(\mathrm{~m}, 1 \mathrm{H}), 6.80(\mathrm{dt}, J=1.1,6.8 \mathrm{~Hz}, 1 \mathrm{H}) ;{ }^{13} \mathrm{C} \mathrm{NMR}\left(100 \mathrm{MHz}, \mathrm{CDCl}_{3}\right)$ $\delta 147.3,140.8,132.6,131.5,127.8,127.3,127.0,124.8,124.4,124.3,124.1,121.0,117.8,111.3,111.1$; HRMS (APCI) $m / z$ calcd for $\mathrm{C}_{15} \mathrm{H}_{10} \mathrm{ClN}_{2}{ }^{+}\left([\mathrm{M}+\mathrm{H}]^{+}\right)$253.0527, found 253.0527.

3-Bromonaphtho[1',2':4,5]imidazo[1,2-a]pyridine (3e)

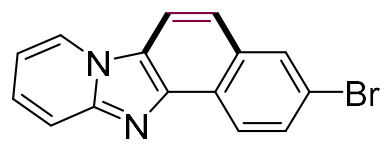

Purified by silica gel column chromatography (eluent: hexane/EtOAc $=1 / 1), 63 \mathrm{mg}(71 \%$ yield), white solid, mp 181-183 ${ }^{\circ} \mathrm{C} ;{ }^{1} \mathrm{H}$ NMR $\left(400 \mathrm{MHz}, \mathrm{CDCl}_{3}\right) \delta 8.66(\mathrm{~d}, J=8.8 \mathrm{~Hz}, 1 \mathrm{H}), 8.42(\mathrm{td}, J=1.1,6.8 \mathrm{~Hz}$, $1 \mathrm{H}), 8.10(\mathrm{~d}, J=2.0 \mathrm{~Hz}, 1 \mathrm{H}), 7.72-7.87(\mathrm{~m}, 3 \mathrm{H}), 7.56(\mathrm{~d}, J=8.8 \mathrm{~Hz}, 1 \mathrm{H}), 7.38-7.46(\mathrm{~m}, 1 \mathrm{H}), 6.93(\mathrm{dt}, J$ $=1.0,6.8 \mathrm{~Hz}, 1 \mathrm{H}) ;{ }^{13} \mathrm{C} \mathrm{NMR}\left(100 \mathrm{MHz}, \mathrm{CDCl}_{3}\right) \delta 147.5,141.0,133.2,130.6,129.7,128.0,125.2,124.7$, 124.41, 124.36, 121.1, 119.8, 118.0, 111.5, 111.2; HRMS (APCI) $m / z$ calcd for $\mathrm{C}_{15} \mathrm{H}_{10} \mathrm{BrN}_{2}{ }^{+}\left([\mathrm{M}+\mathrm{H}]^{+}\right)$ 297.0022, found 297.023.

3-Phenylnaphtho[1',2':4,5]imidazo[1,2-a]pyridine (3f)

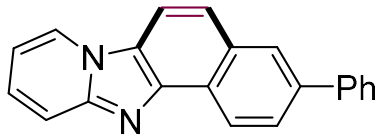


Purified by silica gel column chromatography (eluent: hexane/EtOAc $=1 / 1), 67 \mathrm{mg}(76 \%$ yield), white solid, mp 196-197 ${ }^{\circ} \mathrm{C} ;{ }^{1} \mathrm{H}$ NMR $\left(400 \mathrm{MHz}, \mathrm{CDCl}_{3}\right) \delta 8.88(\mathrm{~d}, J=8.8 \mathrm{~Hz}, 1 \mathrm{H}), 8.35(\mathrm{~d}, J=6.8 \mathrm{~Hz}, 1 \mathrm{H})$, $8.15(\mathrm{~d}, J=1.6 \mathrm{~Hz}, 1 \mathrm{H}), 7.97(\mathrm{dd}, J=1.8,8.4 \mathrm{~Hz}, 1 \mathrm{H}), 7.73-7.85(\mathrm{~m}, 4 \mathrm{H}), 7.68(\mathrm{~d}, J=8.8 \mathrm{~Hz}, 1 \mathrm{H}), 7.46-$ $7.52(\mathrm{~m}, 2 \mathrm{H}), 7.31-7.42(\mathrm{~m}, 2 \mathrm{H}), 6.83(\mathrm{dt}, J=1.1,6.8 \mathrm{~Hz}, 1 \mathrm{H}) ;{ }^{13} \mathrm{C}$ NMR $\left(100 \mathrm{MHz}, \mathrm{CDCl}_{3}\right) \delta 147.3$, 141.2 , 141.0, 138.6, 132.3, 128.9, 127.6, 127.5, 127.3, 126.6, 126.0, 125.8, 124.3, 123.5, 122.6, 117.9, 111.2, 110.4 (1C overlapped); HRMS (APCI) $m / z$ calcd for $\mathrm{C}_{21} \mathrm{H}_{15} \mathrm{~N}_{2}{ }^{+}\left([\mathrm{M}+\mathrm{H}]^{+}\right)$295.1230, found 295.1229.

Naphtho[1',2':4,5]imidazo[1,2-a]pyridine-3-carbonitrile (3g)

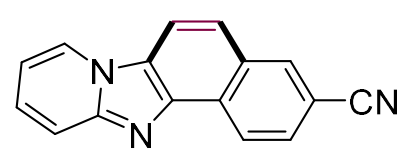

Purified by silica gel column chromatography (eluent: hexane/EtOAc $=1 / 1), 58 \mathrm{mg}(79 \%$ yield), white solid, mp 248-249 ${ }^{\circ} \mathrm{C} ;{ }^{1} \mathrm{H}$ NMR $\left(400 \mathrm{MHz}, \mathrm{CDCl}_{3}\right) \delta 8.82(\mathrm{~d}, J=8.4 \mathrm{~Hz}, 1 \mathrm{H}), 8.46(\mathrm{~d}, J=6.8 \mathrm{~Hz}, 1 \mathrm{H})$, $8.27(\mathrm{~d}, J=1.6 \mathrm{~Hz}, 1 \mathrm{H}), 7.94(\mathrm{~d}, J=8.8 \mathrm{~Hz}, 1 \mathrm{H}), 7.75-7.86(\mathrm{~m}, 2 \mathrm{H}), 7.66(\mathrm{~d}, J=8.8 \mathrm{~Hz}, 1 \mathrm{H}), 7.44-7.52$ $(\mathrm{m}, 1 \mathrm{H}), 6.99(\mathrm{dt}, J=1.1,6.8 \mathrm{~Hz}, 1 \mathrm{H}) ;{ }^{13} \mathrm{C} \mathrm{NMR}\left(100 \mathrm{MHz}, \mathrm{CDCl}_{3}\right) \delta 147.8,140.5,134.1,130.8,128.6$, 128.5, 127.3 125.8, 124.5, 124.1, 121.8, 119.4, 118.2, 112.0, 109.1 (1C overlapped); HRMS (APCI) $\mathrm{m} / \mathrm{z}$ calcd for $\mathrm{C}_{16} \mathrm{H}_{10} \mathrm{~N}_{3}^{+}\left([\mathrm{M}+\mathrm{H}]^{+}\right) 244.0869$, found 244.0869.

2-Methylnaphtho[1',2':4,5]imidazo[1,2-a]pyridine (3h)

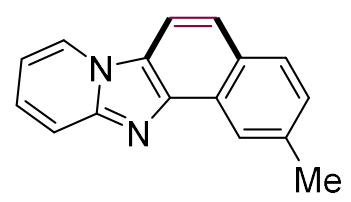

Purified by silica gel column chromatography (eluent: hexane/EtOAc $=1 / 1), 47 \mathrm{mg}(68 \%$ yield), white solid, mp 144-146 ${ }^{\circ} \mathrm{C} ;{ }^{1} \mathrm{H} \mathrm{NMR}\left(400 \mathrm{MHz}, \mathrm{CDCl}_{3}\right) \delta 8.62(\mathrm{~s}, 1 \mathrm{H}), 8.34(\mathrm{dt}, J=1.1,6.8 \mathrm{~Hz}, 1 \mathrm{H}), 7.86(\mathrm{~d}$, $J=8.8 \mathrm{~Hz}, 1 \mathrm{H}), 7.79(\mathrm{td}, J=1.1,9.2 \mathrm{~Hz}, 1 \mathrm{H}), 7.71(\mathrm{~d}, J=8.8 \mathrm{~Hz}, 1 \mathrm{H}), 7.62$ (d, $J=9.2 \mathrm{~Hz}, 1 \mathrm{H}), 7.29$ $7.42(\mathrm{~m}, 2 \mathrm{H}), 6.81(\mathrm{dt}, J=1.1 .6 .8 \mathrm{~Hz}, 1 \mathrm{H}), 2.62(\mathrm{~s}, 3 \mathrm{H}) ;{ }^{13} \mathrm{C} \mathrm{NMR}\left(100 \mathrm{MHz}, \mathrm{CDCl}_{3}\right) \delta 147.1,140.8$, 136.6, 130.0, 128.4, 127.9, 127.3, 126.8, 124.3, 122.3, 122.2, 117.9, 111.0, 109.0, 21.9 (1C overlapped). HRMS (APCI) $m / z$ calcd for $\mathrm{C}_{16} \mathrm{H}_{13} \mathrm{~N}_{2}{ }^{+}\left([\mathrm{M}+\mathrm{H}]^{+}\right)$233.1073, found 233.1078 .

2-Bromonaphtho[1',2':4,5]imidazo[1,2-a]pyridine (3i)

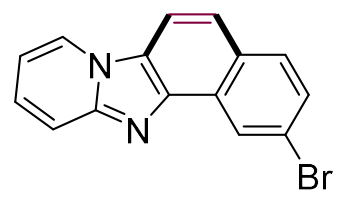

Purified by silica gel column chromatography (eluent: hexane/EtOAc $=1 / 1), 67 \mathrm{mg}(75 \%$ yield), white solid, mp 200-202 ${ }^{\circ} \mathrm{C} ;{ }^{1} \mathrm{H} \mathrm{NMR}\left(400 \mathrm{MHz}, \mathrm{CDCl}_{3}\right) \delta 8.90(\mathrm{~d}, J=2.0 \mathrm{~Hz}, 1 \mathrm{H}), 8.33$ (td, $J=1.1,6.8 \mathrm{~Hz}$, 
1H), 7.71-7.77 (m, 3H), 7.51-7.60 (m, 2H), 7.33-7.41 (m, 1H), $6.88(\mathrm{dt}, J=1.1,6.8 \mathrm{~Hz}, 1 \mathrm{H}) ;{ }^{13} \mathrm{C}$ NMR $\left(100 \mathrm{MHz}, \mathrm{CDCl}_{3}\right) \delta 147.3,140.0,130.2,130.0,129.0,127.9,127.7,125.4,124.6,124.4,121.7,120.7$, 117.9, 111.4, 110.4; HRMS (APCI) $m / z$ calcd for $\mathrm{C}_{15} \mathrm{H}_{10} \mathrm{BrN}_{2}{ }^{+}\left([\mathrm{M}+\mathrm{H}]^{+}\right)$297.0022, found 297.0027 .

Anthra[1',2':4,5]imidazo[1,2-a]pyridine (3j)

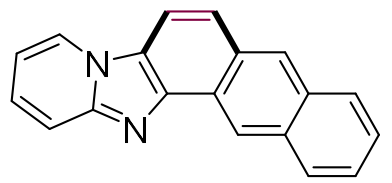

Purified by silica gel column chromatography (eluent: hexane/EtOAc $=1 / 1), 49 \mathrm{mg}(61 \%$ yield), white solid, mp 215-217 ${ }^{\circ} \mathrm{C} ;{ }^{1} \mathrm{H}$ NMR (400 MHz, $\left.\mathrm{CDCl}_{3}\right) \delta 9.30$ (s, 1H), 8.39 (s, 1H), $8.22(\mathrm{~d}, J=6.8 \mathrm{~Hz}, 1 \mathrm{H})$, $8.14(\mathrm{~d}, J=8.1 \mathrm{~Hz}, 1 \mathrm{H}), 7.99(\mathrm{~d}, J=8.1 \mathrm{~Hz}, 1 \mathrm{H}), 7.80(\mathrm{~d}, J=9.0 \mathrm{~Hz}, 1 \mathrm{H}), 7.57-7.68(\mathrm{~m}, 2 \mathrm{H}), 7.45-7.55$ (m, 2H), 7.24-7.32 (m, 1H), $6.78(\mathrm{dt}, J=1.1,6.8 \mathrm{~Hz}, 1 \mathrm{H}) ;{ }^{13} \mathrm{C} \mathrm{NMR}\left(100 \mathrm{MHz}, \mathrm{CDCl}_{3}\right) \delta$ 146.7, 141.0, $131.9,131.5,130.6,128.4,128.2,127.2,126.7,125.7,125.5,125.4$, 123.9, 123.0, 121.4, 117.8, 111.5, 110.6 (1C overlapped); HRMS (APCI) $m / z$ calcd for $\mathrm{C}_{19} \mathrm{H}_{13} \mathrm{~N}_{2}{ }^{+}\left([\mathrm{M}+\mathrm{H}]^{+}\right)$269.1073, found 269.1089.

Thieno[3",2":5',6']benzo[1',2':4,5]imidazo[1,2-a]pyridine (3k)

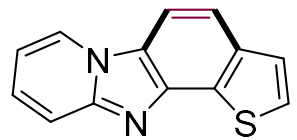

Purified by silica gel column chromatography (eluent: hexane/EtOAc $=1 / 1), 43 \mathrm{mg}(64 \%$ yield), white solid, mp 200-201 ${ }^{\circ} \mathrm{C} ;{ }^{1} \mathrm{H}$ NMR (400 MHz, $\left.\mathrm{CDCl}_{3}\right) \delta 8.41$ (td, $\left.J=1.1,6.8 \mathrm{~Hz}, 1 \mathrm{H}\right), 7.68-7.79$ (m, 3H), 7.47-7.55 (m, 2H), 7.34-7.42 (m, 1H), $6.85(\mathrm{dt}, J=1.1,6.8 \mathrm{~Hz}, 1 \mathrm{H}) ;{ }^{13} \mathrm{C} \mathrm{NMR}\left(100 \mathrm{MHz}, \mathrm{CDCl}_{3}\right) \delta 148.0$, $139.8,138.2,130.0,128.5,125.4,125.0,124.9,124.8,117.8,117.2,111.0,107.7$; HRMS (APCI) $m / z$ calcd for $\mathrm{C}_{13} \mathrm{H}_{9} \mathrm{~N}_{2} \mathrm{~S}^{+}\left([\mathrm{M}+\mathrm{H}]^{+}\right)$225.0481, found 225.0478 .

Thieno[3",4":5',6']benzo[1',2':4,5]imidazo[1,2-a]pyridine (31)

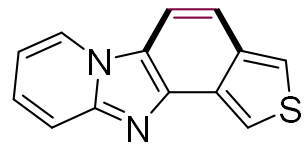

Purified by silica gel column chromatography (eluent: hexane/EtOAc $=1 / 1), 30 \mathrm{mg}(44 \%$ yield), white solid, $\mathrm{mp}=201-204{ }^{\circ} \mathrm{C} ;{ }^{1} \mathrm{H}$ NMR $\left(400 \mathrm{MHz}, \mathrm{CDCl}_{3}\right) \delta 8.44-8.48(\mathrm{~m}, 1 \mathrm{H}), 8.09(\mathrm{~d}, J=5.2 \mathrm{~Hz}, 1 \mathrm{H}), 7.75-$ $7.81(\mathrm{~m}, 3 \mathrm{H}), 7.63(\mathrm{~d}, J=5.6 \mathrm{~Hz}, 1 \mathrm{H}), 7.38-7.46(\mathrm{~m}, 1 \mathrm{H}), 6.89(\mathrm{t}, J=6.6 \mathrm{~Hz}, 1 \mathrm{H}) ;{ }^{13} \mathrm{C} \mathrm{NMR}(100 \mathrm{MHz}$, $\left.\mathrm{CDCl}_{3}\right) \delta 147.7,140.1,137.7,131.4,128.4,126.8,125.2,124.9,121.6,117.9,115.6,110.9,107.5 ;$ HRMS (APCI) $m / z$ calcd for $\mathrm{C}_{13} \mathrm{H}_{9} \mathrm{~N}_{2} \mathrm{~S}^{+}\left([\mathrm{M}+\mathrm{H}]^{+}\right)$225.0481, found 225.0482 . 


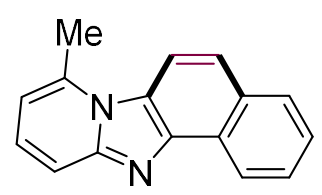

Purified by silica gel column chromatography (eluent: hexane/EtOAc $=1 / 1), 58 \mathrm{mg}(84 \%$ yield), white solid, mp 156-158 ${ }^{\circ} \mathrm{C} ;{ }^{1} \mathrm{H}$ NMR (400 MHz, $\left.\mathrm{CDCl}_{3}\right) \delta 8.82-8.87(\mathrm{~m}, 1 \mathrm{H}), 7.98(\mathrm{~d}, J=9.2 \mathrm{~Hz}, 1 \mathrm{H}), 7.91$ $(\mathrm{d}, J=8.4 \mathrm{~Hz}, 1 \mathrm{H}), 7.63-7.72(\mathrm{~m}, 2 \mathrm{H}), 7.54-7.60(\mathrm{~m}, 1 \mathrm{H}), 7.51(\mathrm{~d}, J=9.2 \mathrm{~Hz}, 1 \mathrm{H}), 7.21-7.28(\mathrm{~m}, 1 \mathrm{H})$, $6.53(\mathrm{~d}, J=6.4 \mathrm{~Hz}, 1 \mathrm{H}), 2.89(\mathrm{~s}, 3 \mathrm{H}) ;{ }^{13} \mathrm{C} \mathrm{NMR}\left(100 \mathrm{MHz}, \mathrm{CDCl}_{3}\right) \delta 148.4,141.7,137.9,131.2,127.9$, 127.6, 126.5, 126.2, 126.0, 125.5, 123.0, 121.3, 115.3, 114.1, 111.8, 21.3; HRMS (APCI) $\mathrm{m} / \mathrm{z}$ calcd for $\mathrm{C}_{16} \mathrm{H}_{13} \mathrm{~N}_{2}^{+}\left([\mathrm{M}+\mathrm{H}]^{+}\right)$233.1073, found 233.1074

10-Chloronaphtho[1',2':4,5]imidazo[1,2-a]pyridine (3n)

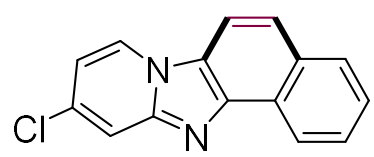

Purified by silica gel column chromatography (eluent: hexane/EtOAc $=1 / 1), 62 \mathrm{mg}(82 \%$ yield), white solid, mp 236-238 ${ }^{\circ} \mathrm{C} ;{ }^{1} \mathrm{H}$ NMR $\left(400 \mathrm{MHz}, \mathrm{CDCl}_{3}\right) \delta 8.77(\mathrm{~d}, J=8.4 \mathrm{~Hz}, 1 \mathrm{H}), 8.32(\mathrm{~d}, J=7.2 \mathrm{~Hz}, 1 \mathrm{H})$, $7.98(\mathrm{~d}, J=8.4 \mathrm{~Hz}, 1 \mathrm{H}), 7.75-7.82(\mathrm{~m}, 2 \mathrm{H}), 7.67-7.74(\mathrm{~m}, 2 \mathrm{H}), 7.56-7.64(\mathrm{~m}, 1 \mathrm{H}), 6.86(\mathrm{dd}, J=2.0,7.2$ $\mathrm{Hz}, 1 \mathrm{H}) ;{ }^{13} \mathrm{C}$ NMR $\left(100 \mathrm{MHz}, \mathrm{CDCl}_{3}\right) \delta 146.8,141.6,134.0,132.0,128.6,126.8,126.7,126.2,124.5$, 124.1, 123.0, 122.9, 116.7, 112.9, 109.7; HRMS (APCI) $\mathrm{m} / z$ calcd for $\mathrm{C}_{15} \mathrm{H}_{10} \mathrm{ClN}_{2}{ }^{+}\left([\mathrm{M}+\mathrm{H}]^{+}\right) 253.0527$ found 253.0525 .

10-Chloro-3-methylnaphtho[1',2':4,5]imidazo[1,2-a]pyridine (3o)

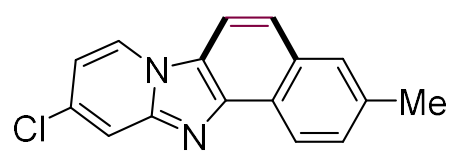

Purified by silica gel column chromatography (eluent: hexane/EtOAc $=1 / 1), 68 \mathrm{mg}(85 \%$ yield), white solid, mp 193-194 ${ }^{\circ} \mathrm{C} ;{ }^{1} \mathrm{H}$ NMR $\left(400 \mathrm{MHz}, \mathrm{CDCl}_{3}\right) \delta 8.60(\mathrm{~d}, J=8.4 \mathrm{~Hz}, 1 \mathrm{H}), 8.10$ (dd, $J=0.8,7.2 \mathrm{~Hz}$, $1 \mathrm{H}), 7.64-7.72(\mathrm{~m}, 2 \mathrm{H}), 7.46-7.58(\mathrm{~m}, 3 \mathrm{H}), 6.70(\mathrm{dd}, J=7.2,2.0 \mathrm{~Hz}, 1 \mathrm{H}) ;{ }^{13} \mathrm{C} \mathrm{NMR}\left(100 \mathrm{MHz}, \mathrm{CDCl}_{3}\right)$ $\delta 146.6,141.5,135.8,133.7,132.2,128.7,127.9,124.4,124.3,123.6,122.7,122.4,116.4,112.6,109.5$, 21.8; HRMS (APCI) $m / z$ calcd for $\mathrm{C}_{16} \mathrm{H}_{12} \mathrm{ClN}_{2}{ }^{+}\left([\mathrm{M}+\mathrm{H}]^{+}\right)$267.0684, found 267.0688.

Benzo $[d]$ naphtho[1',2':4,5]imidazo[2,1-b]thiazole (3p)

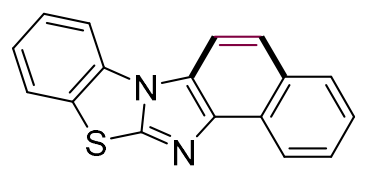


Purified by silica gel column chromatography (eluent: hexane/EtOAc $=3 / 1), 58 \mathrm{mg}(70 \%$ yield), white solid, mp 169-170 ${ }^{\circ} \mathrm{C} ;{ }^{1} \mathrm{H}$ NMR (400 MHz, $\left.\mathrm{CDCl}_{3}\right) \delta 8.54-8.59(\mathrm{~m}, 1 \mathrm{H}), 7.81(\mathrm{~d}, J=8.4 \mathrm{~Hz}, 1 \mathrm{H}), 7.74$ $(\mathrm{d}, J=8.8 \mathrm{~Hz}, 1 \mathrm{H}), 7.65-7.69(\mathrm{~m}, 1 \mathrm{H}), 7.51-7.61(\mathrm{~m}, 3 \mathrm{H}), 7.38-7.46(\mathrm{~m}, 1 \mathrm{H}), 7.28-7.36(\mathrm{~m}, 1 \mathrm{H}), 7.14-$ $7.22(\mathrm{~m}, 1 \mathrm{H}) ;{ }^{13} \mathrm{C} \mathrm{NMR}\left(100 \mathrm{MHz}, \mathrm{CDCl}_{3}\right) \delta$ 152.4, 143.6, 132.8, 130.3, 129.2, 128.2, 126.6, 126.4, 126.29, 126.26, 125.0, 124.3, 124.1, 122.5, 122.0, 112.3, 110.4; HRMS (APCI) $m / z$ calcd for $\mathrm{C}_{17} \mathrm{H}_{11} \mathrm{~N}_{2} \mathrm{~S}^{+}$ $\left([\mathrm{M}+\mathrm{H}]^{+}\right)$275.0637, found 275.0640 .

Indazolo $[2,3-a]$ quinoline $(\mathbf{6 a})^{4}$

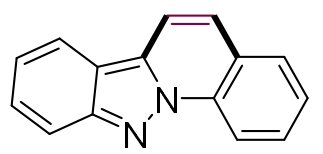

Purified by silica gel column chromatography (eluent: hexane/EtOAc $=4 / 1), 47 \mathrm{mg}(72 \%$ yield), white solid, mp = 109-110 ${ }^{\circ} \mathrm{C} ;{ }^{1} \mathrm{H} \mathrm{NMR}\left(400 \mathrm{MHz}, \mathrm{CDCl}_{3}\right) \delta 8.91(\mathrm{dd}, J=0.4,8.0 \mathrm{~Hz}, 1 \mathrm{H}), 7.93-8.05(\mathrm{~m}, 2 \mathrm{H})$, $7.90(\mathrm{~d}, J=9.2 \mathrm{~Hz}, 1 \mathrm{H}), 7.86(\mathrm{dd}, J=1.6,8.0 \mathrm{~Hz}, 1 \mathrm{H}), 7.71-7.79(\mathrm{~m}, 1 \mathrm{H}), 7.50-7.59$ (m, 3H), 7.22-7.27 $(\mathrm{m}, 1 \mathrm{H}),{ }^{13} \mathrm{C}$ NMR $\left(100 \mathrm{MHz}, \mathrm{CDCl}_{3}\right) \delta 149.2,134.1,132.4,129.4,128.5,128.0,126.1,125.2,123.1$, 120.8, 119.7, 117.2, 116.8, 116.6, 115.6; HRMS (APCI) $\mathrm{m} / z$ calcd for $\mathrm{C}_{15} \mathrm{H}_{11} \mathrm{~N}_{2}{ }^{+}\left([\mathrm{M}+\mathrm{H}]^{+}\right)$219.0917, found 219.0917 .

3-Methylindazolo[2,3-a]quinoline $(\mathbf{6 b})^{5}$

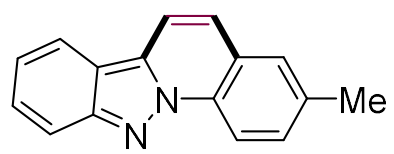

Purified by silica gel column chromatography (eluent: hexane/EtOAc $=4 / 1), 35 \mathrm{mg}(50 \%$ yield), white solid, mp 114-115 ${ }^{\circ} \mathrm{C} ;{ }^{1} \mathrm{H}$ NMR $\left(400 \mathrm{MHz}, \mathrm{CDCl}_{3}\right) \delta 8.80(\mathrm{~d}, J=8.4 \mathrm{~Hz}, 1 \mathrm{H}), 8.04$ (td, $J=1.2,8.4 \mathrm{~Hz}$, 1H), $7.96(\mathrm{td}, J=1.2,8.4 \mathrm{~Hz}, 1 \mathrm{H}), 7.90$ (d, $J=9.2 \mathrm{~Hz}, 1 \mathrm{H}), 7.50-7.65$ (m, 4H), 7.20-7.28 (m, 1H), 2.54 $(\mathrm{s}, 3 \mathrm{H}) ;{ }^{13} \mathrm{C} \mathrm{NMR}\left(100 \mathrm{MHz}, \mathrm{CDCl}_{3}\right) \delta 149.1,136.0,132.3,132.1,131.0,127.9,127.8,125.3,122.9$, 120.6, 119.7, 116.9, 116.8, 116.5, 115.5, 21.3; HRMS (APCI) $m / z$ calcd for $\mathrm{C}_{16} \mathrm{H}_{13} \mathrm{~N}_{2}{ }^{+}\left([\mathrm{M}+\mathrm{H}]^{+}\right)$ 233.1073, found 233.1066.

3-chloroindazolo[2,3-a] quinoline $(\mathbf{6 c})^{5}$

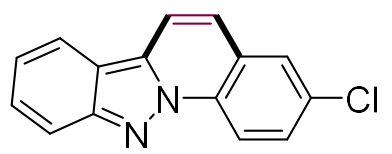

Purified by silica gel column chromatography (eluent: hexane/EtOAc $=4 / 1), 54 \mathrm{mg}(71 \%$ yield), white solid, mp 163-164 ${ }^{\circ} \mathrm{C} ;{ }^{1} \mathrm{H} \mathrm{NMR}\left(400 \mathrm{MHz}, \mathrm{CDCl}_{3}\right) \delta 8.87(\mathrm{~d}, J=9.2 \mathrm{~Hz}, 1 \mathrm{H}), 8.05(\mathrm{~d}, J=8.4 \mathrm{~Hz}, 1 \mathrm{H})$, 
7.91-8.01 (m, 2H), $7.88(\mathrm{~d}, J=2.4 \mathrm{~Hz}, 1 \mathrm{H}), 7.72(\mathrm{dd}, J=2.4,8.8 \mathrm{~Hz}, 1 \mathrm{H}), 7.50-7.60(\mathrm{~m}, 2 \mathrm{H}), 7.24-7.30$ $(\mathrm{m}, 1 \mathrm{H}) ;{ }^{13} \mathrm{C}$ NMR $\left(100 \mathrm{MHz}, \mathrm{CDCl}_{3}\right) \delta 149.3,132.6,132.2,131.8,129.8,128.3,127.5,126.2,121.8$, 121.2, 119.7, 118.8, 116.88, 116.85, 116.7; HRMS (APCI) $m / z$ calcd for $\mathrm{C}_{15} \mathrm{H}_{10} \mathrm{ClN}_{2}{ }^{+}\left([\mathrm{M}+\mathrm{H}]^{+}\right)$253.0527, found 253.0531 .

9-Fluoroindazolo[2,3-a]quinoline (6d)

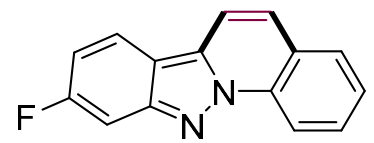

Purified by silica gel column chromatography (eluent: hexane/EtOAc $=4 / 1), 43 \mathrm{mg}(60 \%$ yield), white solid, mp 130-132 ${ }^{\circ} \mathrm{C} ;{ }^{1} \mathrm{H}$ NMR $\left(400 \mathrm{MHz}, \mathrm{CDCl}_{3}\right) \delta 8.85(\mathrm{~d}, J=8.6 \mathrm{~Hz}, 1 \mathrm{H}), 7.71-7.94(\mathrm{~m}, 4 \mathrm{H}), 7.50$ $7.61(\mathrm{~m}, 3 \mathrm{H}), 7.33(\mathrm{dt}, J=2.4,9.2 \mathrm{~Hz}, 1 \mathrm{H}) ;{ }^{13} \mathrm{C} \mathrm{NMR}\left(100 \mathrm{MHz}, \mathrm{CDCl}_{3}\right) \delta 157.7(\mathrm{~d}, J=238.0 \mathrm{~Hz})$, 146.3, 134.2, 132.4 (d, $J=7.7 \mathrm{~Hz}), 129.5,128.5,126.3,125.2,122.8,118.9$ (d, $J=28.2 \mathrm{~Hz}), 118.5$ (d, $J$ $=9.3 \mathrm{~Hz}), 117.0,116.0(\mathrm{~d}, J=11.8 \mathrm{~Hz}), 115.5,102.9(\mathrm{~d}, J=25.1) ;{ }^{19} \mathrm{~F}\left(376 \mathrm{MHz}, \mathrm{CDCl}_{3}\right) \delta-120.7$; HRMS (APCI) $m / z$ calcd for $\mathrm{C}_{15} \mathrm{H}_{10} \mathrm{FN}_{2}{ }^{+}\left([\mathrm{M}+\mathrm{H}]^{+}\right)$237.0823, found 237.0823.

3-Methylbenzo[g]pyrido[1,2-b]indazole $(\mathbf{7 a})^{6}$

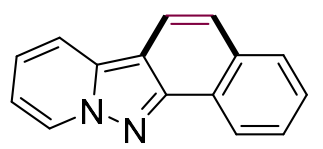

Purified by silica gel column chromatography (eluent: hexane/EtOAc $=2 / 1), 53 \mathrm{mg}(80 \%$ yield), white solid, mp $=137-138{ }^{\circ} \mathrm{C} ;{ }^{1} \mathrm{H}$ NMR $\left(400 \mathrm{MHz}, \mathrm{CDCl}_{3}\right) \delta 8.71-8.81(\mathrm{~m}, 2 \mathrm{H}), 7.88-7.98(\mathrm{~m}, 2 \mathrm{H}), 7.85(\mathrm{~d}, J$ $=8.8 \mathrm{~Hz}, 1 \mathrm{H}), 7.56-7.68(\mathrm{~m}, 2 \mathrm{H}), 7.47(\mathrm{~d}, J=8.8 \mathrm{~Hz}, 1 \mathrm{H}), 7.20-7.28(\mathrm{~m}, 1 \mathrm{H}), 7.01(\mathrm{dd}, J=1.2,6.8 \mathrm{~Hz}$, $1 \mathrm{H}) ;{ }^{13} \mathrm{C} \mathrm{NMR}\left(100 \mathrm{MHz}, \mathrm{CDCl}_{3}\right) \delta 147.6,135.7,133.6,128.5,128.4,127.2,126.3,124.3,123.1,122.7$, 121.5, 117.6, 117.5, 114.7, 111.0; HRMS (APCI) $m / z$ calcd for $\mathrm{C}_{15} \mathrm{H}_{11} \mathrm{~N}_{2}{ }^{+}\left([\mathrm{M}+\mathrm{H}]^{+}\right) 219.0917$, found 219.0913.

3-Methylbenzo[g]pyrido[1,2-b]indazole (7b)

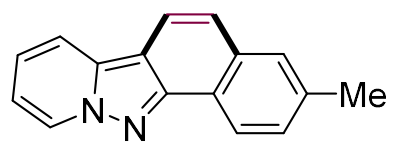

Purified by silica gel column chromatography (eluent: hexane/EtOAc $=2 / 1), 63 \mathrm{mg}(90 \%$ yield), white solid, mp 150-151 ${ }^{\circ} \mathrm{C} ;{ }^{1} \mathrm{H}$ NMR $\left(400 \mathrm{MHz}, \mathrm{CDCl}_{3}\right) \delta 8.78(\mathrm{~d}, J=6.8 \mathrm{~Hz}, 1 \mathrm{H}), 8.62(\mathrm{~d}, J=8.0 \mathrm{~Hz}, 1 \mathrm{H})$, $7.95(\mathrm{~d}, J=8.8 \mathrm{~Hz}, 1 \mathrm{H}), 7.83$ (d, $J=8.8 \mathrm{~Hz}, 1 \mathrm{H}), 7.69$ (s, 1H), 7.47 (dd, $J=1.2,8.0 \mathrm{~Hz}, 1 \mathrm{H}), 7.41$ (d, $J$ $=8.8 \mathrm{~Hz}, 1 \mathrm{H}), 7.22-7.28(\mathrm{~m}, 1 \mathrm{H}), 7.01(\mathrm{t}, J=6.8 \mathrm{~Hz}, 1 \mathrm{H}), 2.55(\mathrm{~s}, 3 \mathrm{H}) ;{ }^{13} \mathrm{C} \mathrm{NMR}\left(100 \mathrm{MHz}, \mathrm{CDCl}_{3}\right) \delta$ 147.7, 137.0, 135.7, 133.8, 128.4, 128.1, 128.0, 122.9, 122.6, 122.0, 121.3, 117.6, 117.4, 114.5, 110.7, 21.8; HRMS (APCI) $m / z$ calcd for $\mathrm{C}_{16} \mathrm{H}_{13} \mathrm{~N}_{2}{ }^{+}\left([\mathrm{M}+\mathrm{H}]^{+}\right)$233.1073, found 233.1065. 
3-Methoxybenzo[g]pyrido[1,2- $b]$ indazole (7c)

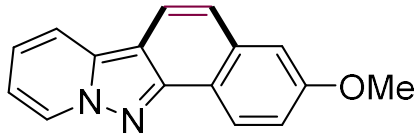

Purified by silica gel column chromatography (eluent: hexane/EtOAc $=2 / 1), 63 \mathrm{mg}(85 \%$ yield), white solid, mp 160-162 ${ }^{\circ} \mathrm{C} ;{ }^{1} \mathrm{H}$ NMR $\left(400 \mathrm{MHz}, \mathrm{CDCl}_{3}\right) \delta 8.76(\mathrm{~d}, J=6.8 \mathrm{~Hz}, 1 \mathrm{H}), 8.64(\mathrm{~d}, J=9.6 \mathrm{~Hz}, 1 \mathrm{H})$, $7.93(\mathrm{~d}, J=8.6 \mathrm{~Hz}, 1 \mathrm{H}), 7.83$ (d, $J=8.8 \mathrm{~Hz}, 1 \mathrm{H}), 7.39$ (d, $J=8.8 \mathrm{~Hz}, 1 \mathrm{H}), 7.21-7.30(\mathrm{~m}, 3 \mathrm{H}), 6.99(\mathrm{t}, J$ $=6.8 \mathrm{~Hz}, 1 \mathrm{H}), 3.93(\mathrm{~s}, 3 \mathrm{H}) ;{ }^{13} \mathrm{C} \mathrm{NMR}\left(100 \mathrm{MHz}, \mathrm{CDCl}_{3}\right) \delta 158.8,147.8,135.8,135.2,128.4,124.6$, 122.7, 121.0, 118.5, 118.3, 117.3, 116.5, 114.4, 110.1, 108.9, 55.4; HRMS (APCI) $\mathrm{m} / \mathrm{z}$ calcd for $\mathrm{C}_{16} \mathrm{H}_{13} \mathrm{~N}_{2} \mathrm{O}^{+}\left([\mathrm{M}+\mathrm{H}]^{+}\right)$249.1022, found 249.1025.

3-Fluorobenzo $[g]$ pyrido $[1,2-b]$ indazole $(\mathbf{7 d})$

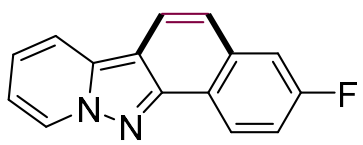

Purified by silica gel column chromatography (eluent: hexane/EtOAc $=2 / 1), 62 \mathrm{mg}(87 \%$ yield), white solid, $\mathrm{mp}=159-160{ }^{\circ} \mathrm{C} ;{ }^{1} \mathrm{H} \mathrm{NMR}\left(400 \mathrm{MHz}, \mathrm{CDCl}_{3}\right) \delta 8.66(\mathrm{td}, J=1.0,6.8 \mathrm{~Hz}, 1 \mathrm{H}), 8.59(\mathrm{dd}, J=5.6$, $9.2 \mathrm{~Hz}, 1 \mathrm{H}), 7.83(\mathrm{td}, J=1.2,8.8 \mathrm{~Hz}, 1 \mathrm{H}), 7.75(\mathrm{dd}, J=0.4,8.8 \mathrm{~Hz}, 1 \mathrm{H}), 7.42(\mathrm{dd}, J=2.4,10.0 \mathrm{~Hz}, 1 \mathrm{H})$, 7.22-7.31 (m, 2H), 7.13-7.20 (m, 1H), $6.94(\mathrm{dt}, J=1.2,6.8 \mathrm{~Hz}, 1 \mathrm{H}) ;{ }^{13} \mathrm{C} \mathrm{NMR}\left(100 \mathrm{MHz}, \mathrm{CDCl}_{3}\right) \delta 161.8$ $(\mathrm{d}, J=245.5 \mathrm{~Hz}), 147.3,135.8,135.0(\mathrm{~d}, J=9.1 \mathrm{~Hz}), 128.4,125.3(\mathrm{~d}, J=8.9 \mathrm{~Hz}), 122.9,120.8,120.6$ $(\mathrm{d}, J=3.8 \mathrm{~Hz}), 119.0,117.4,115.1(\mathrm{~d}, J=23.7 \mathrm{~Hz}), 114.7,112.6(\mathrm{~d}, J=21.1 \mathrm{~Hz}), 110.5 ;{ }^{19} \mathrm{~F}(376 \mathrm{MHz}$, $\left.\mathrm{CDCl}_{3}\right) \delta$-113.8; HRMS (APCI) $m / z$ calcd for $\mathrm{C}_{15} \mathrm{H}_{10} \mathrm{FN}_{2}{ }^{+}\left([\mathrm{M}+\mathrm{H}]^{+}\right)$237.0823, found 237.0823. 


\section{2-3. Reaction of 1a-Br with vinylene carbonate (Scheme 5)}

1a-Br was prepared according to the literature procedure (Tetrahedron Letters, 2012, 53, 297-300). In a $10 \mathrm{~mL}$ round-bottom flask, 2-phenylimidazo[1,2-a]-pyridine (1a) (63 mg, $0.33 \mathrm{mmol})$ was dissolved in MeCN (1.0 mL). NBS (69 mg, $0.4 \mathrm{mmol}$ ) was added in one portion, and the mixture was stirred at room temperature for $2 \mathrm{~h}$. Volatiles were removed in vacuo, and the residue was purified by silica gel column chromatography (eluent: hexane/EtOAc $=2 / 1$ ) to give $\mathbf{1 a - B r}$ as pale yellow oil ( $69 \mathrm{mg}, 77 \%$ yield).

${ }^{1} \mathrm{H}$ NMR $\left(400 \mathrm{MHz}, \mathrm{CDCl}_{3}\right) \delta$ 8.22-8.19 (m, 1H), 8.14-8.12 (m, 2H), 7.67-7.63 (m, 1H), 7.52-7.46 (m, $2 \mathrm{H}), 7.42-7.36(\mathrm{~m}, 1 \mathrm{H}), 7.30-7.26(\mathrm{~m}, 1 \mathrm{H}), 6.97-6.93(\mathrm{~m}, 1 \mathrm{H}) ;{ }^{13} \mathrm{C} \mathrm{NMR}\left(100 \mathrm{MHz}, \mathrm{CDCl}_{3}\right) \delta 145.5$, $142.7,132.9,128.5,128.3,127.9,125.1,124.0,117.7,113.1,91.7$.

To an oven dried screw-top tube were placed 1a-Br (55 mg, $0.2 \mathrm{mmol}, 1.0$ equiv) and $\left[\mathrm{Cp} * \mathrm{Rh}(\mathrm{MeCN})_{3}\right]\left[\mathrm{SbF}_{6}\right]_{2}(6.0 \mathrm{~mol} \%)$. DCE $(1.0 \mathrm{~mL})$ and vinylene carbonate $(0.4 \mathrm{mmol}, 2.0$ equiv) were added via a syringe. The mixture was heated with an oil bath at $120^{\circ} \mathrm{C}$ for $24 \mathrm{~h}$. Volatiles were removed in vacuo, and the residue was purified by silica gel column chromatography to give $3 \mathrm{a}$ ( $7 \mathrm{mg}$, 16\% yield) along with 1a-Br (44 mg, 81\% recovered). 


\section{X-ray crystallographic analysis}

The structures were refined by full-matrix least-squares method using SHELXL-2016/6. ${ }^{7}$ Hydrogen atoms were included in the refinement on calculated positions riding on their carrier atoms. ORTEP-3 programs were used to draw the molecules. ${ }^{8}$ The CCDC numbers are 1990592 (3a), 1990593 (6a), and 1990594 (7a). These data can be obtained free of charge from the Cambridge Crystallographic Data Centre via www.ccdc.cam.ac.uk/data_request/cif.

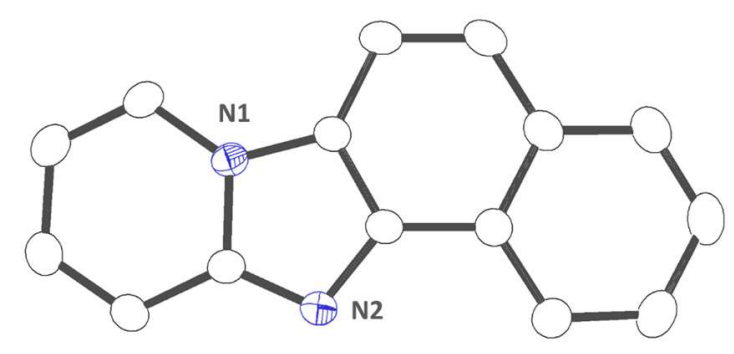

Figure S1. ORTEP drawing for 3a with 50\% thermal ellipsoid. Hydrogen atoms are omitted for clarity.

Table S1. Crystal data for 3a

Crystal system

Space group

Unit cell parameter $[\AA, \operatorname{deg}]$

Cell volume $\left[\AA^{3}\right]$

Z

$\mathrm{R}$ factor $(I>2.0 \sigma(I))$

$\mathrm{R}$ factor (all data)

Rint

Goodness of fit orthorhombic

$P$ bca (No. 61)

$a=7.7432(3)$

$b=12.3301(4)$

$c=22.0964(11)$

2109.64(15)

8

$R 1=0.0460, w R 2=0.1143$

$R 1=0.0525, w R 2=0.1248$

0.0475

1.104 


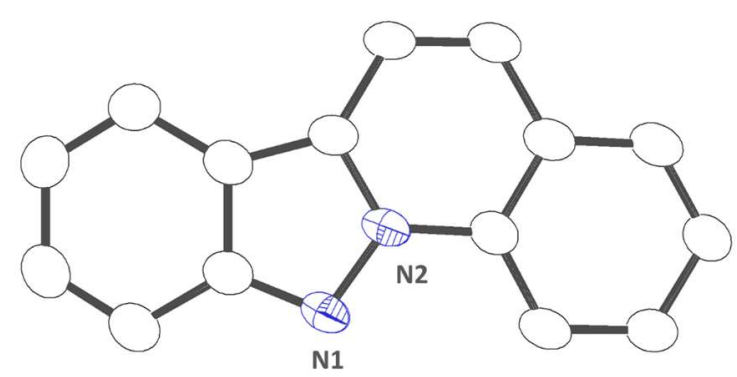

Figure S2. ORTEP drawing for $6 \mathbf{a}$ with 50\% thermal ellipsoid. Hydrogen atoms are omitted for clarity.

Table S2. Crystal data for $\mathbf{6 a}$

Crystal system

Space group

Unit cell parameter $[\AA$, deg]

Cell volume $\left[\AA^{3}\right]$

Z

$\mathrm{R}$ factor $(I>2.0 \sigma(I))$

$\mathrm{R}$ factor (all data)

Rint

Goodness of fit monoclinic

$P 2{ }_{1} / c$ (No. 14)

$a=5.4363(3)$

$b=14.5394(8), \beta=95.925(4)$

$c=13.5819(7)$

1067.79(10)

4

$R 1=0.0508, w R 2=0.1397$

$R 1=0.0569, w R 2=0.1459$

0.0468

1.065 


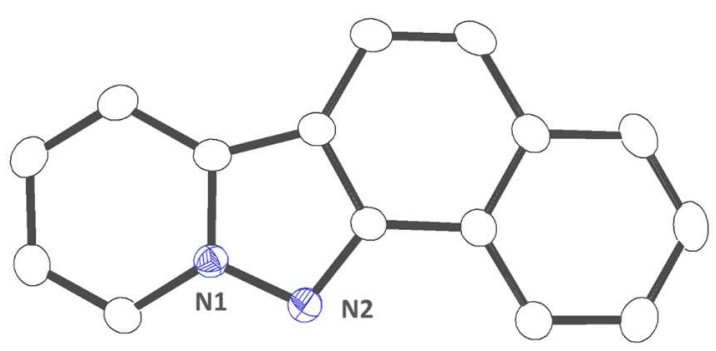

Figure S3. ORTEP drawing for 7a with 50\% thermal ellipsoid. Hydrogen atoms are omitted for clarity.

Table S3. Crystal data for 7a

Crystal system

Space group

Unit cell parameter $[\AA, \operatorname{deg}]$

Cell volume $\left[\AA^{3}\right]$

Z

$\mathrm{R}$ factor $(I>2.0 \sigma(I))$

$\mathrm{R}$ factor (all data)

Rint

Goodness of fit monoclinic

$P 2{ }_{1} / c$ (No. 14)

$a=10.9023(6)$

$b=8.2524(3), \beta=112.505(6)$

$c=12.5947(6)$

1067.79(10)

4

$R 1=0.0435, w R 2=0.1131$

$R 1=0.0505, w R 2=0.1180$

0.0506

1.107 


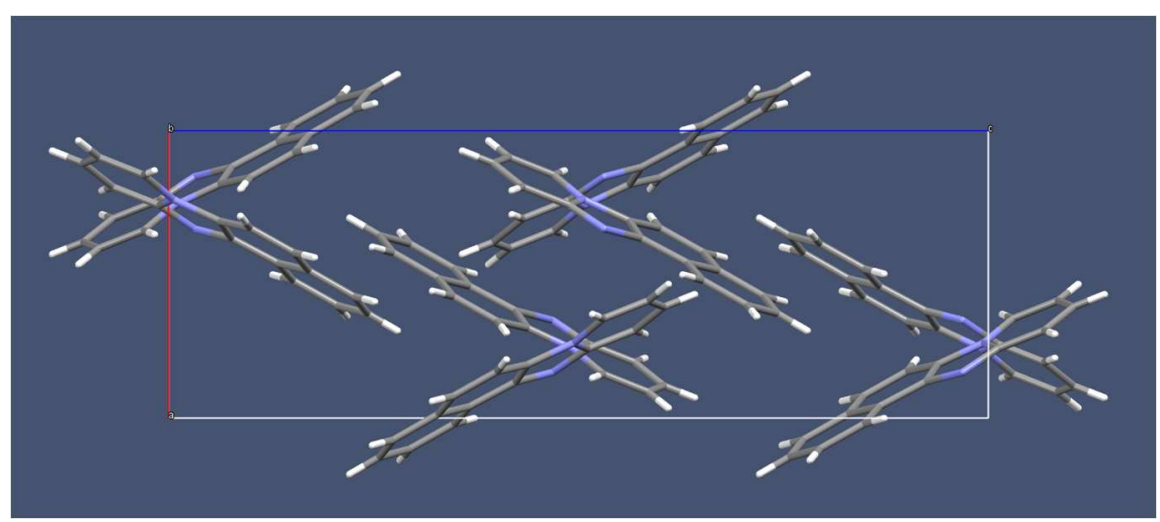

Figure S4. Packing structure of 3a.
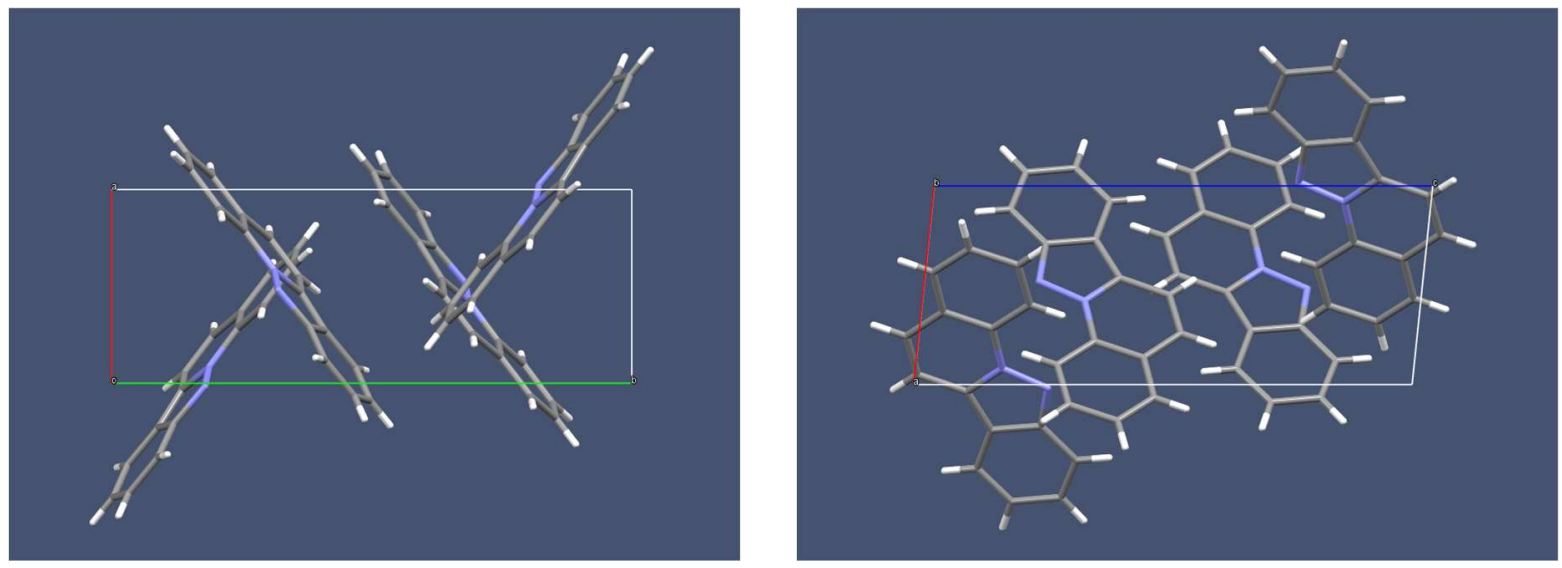

Figure S5. Packing structure of $\mathbf{6 a}$.
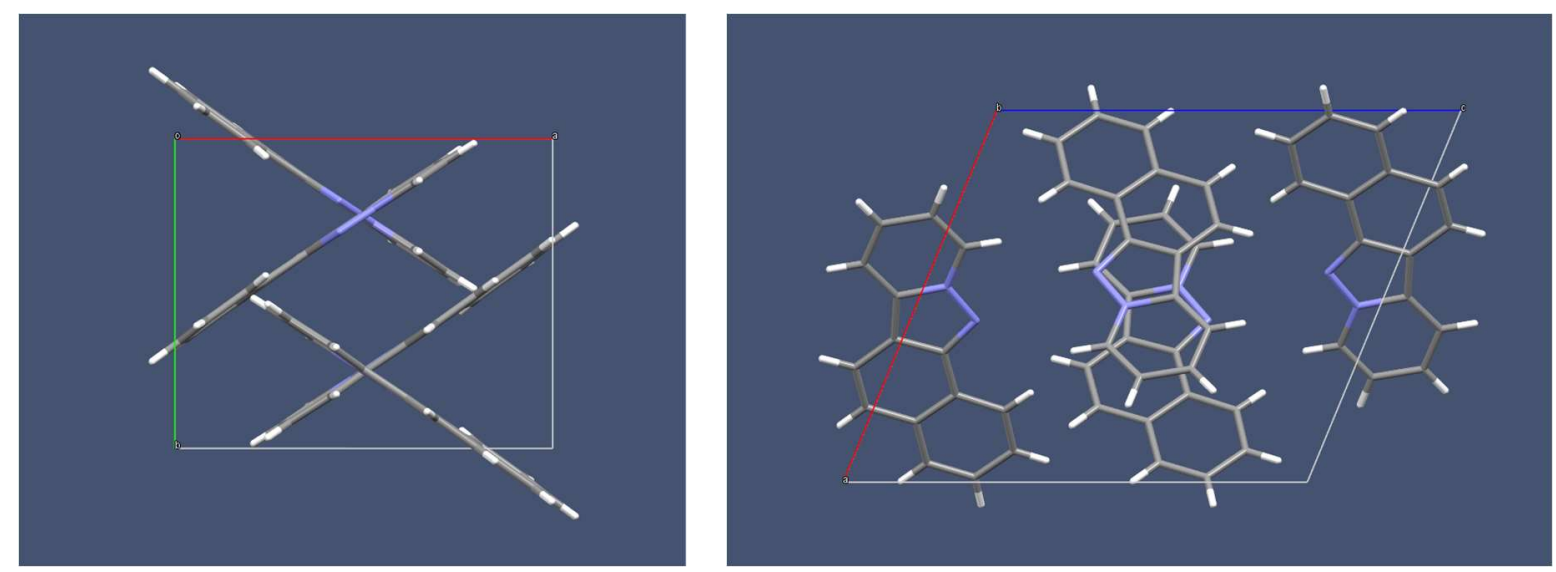

Figure S6. Packing structure of 7a. 


\section{Copy of NMR spectra}

${ }^{1} \mathrm{H} \mathrm{NMR}\left(\mathrm{CDCl}_{3}, 400 \mathrm{MHz}\right)$ of $\mathbf{3 a}$

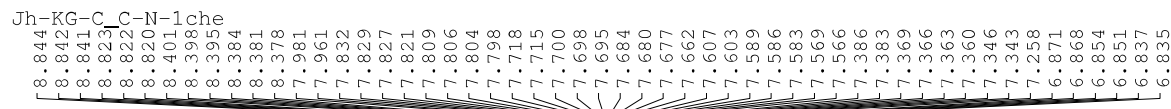

,

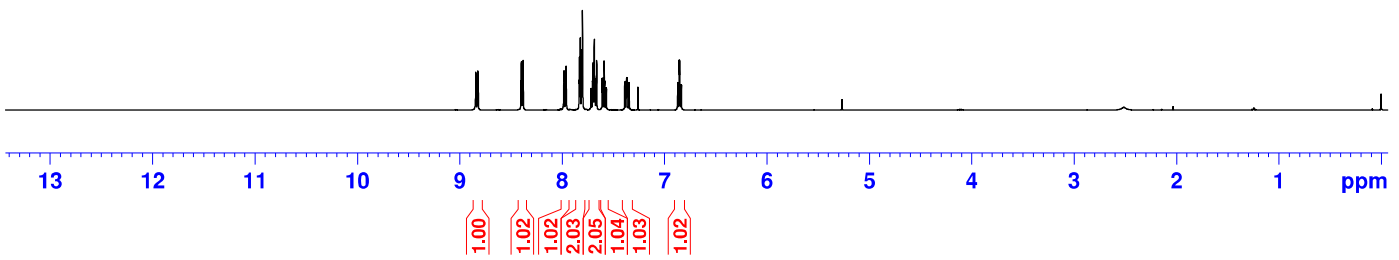

${ }^{13} \mathrm{C} \mathrm{NMR}\left(\mathrm{CDCl}_{3}, 100 \mathrm{MHz}\right)$ of $\mathbf{3 a}$

Jh-KG-C_C-N-1che

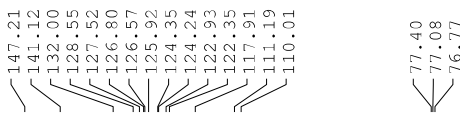

(1)

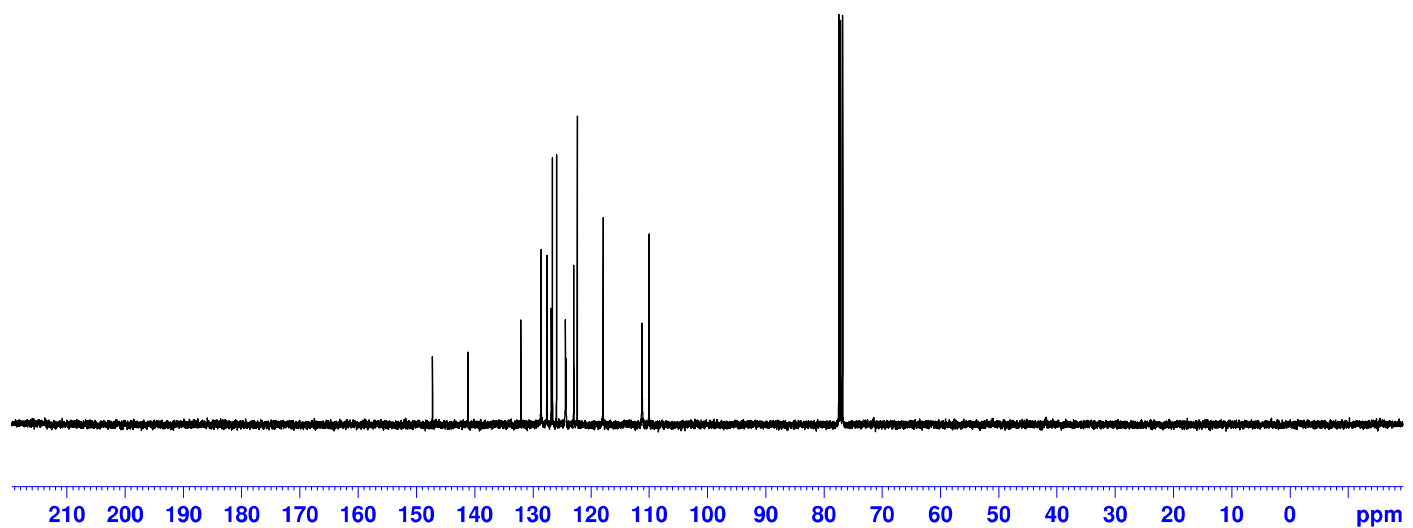


${ }^{1} \mathrm{H} \mathrm{NMR}\left(\mathrm{CDCl}_{3}, 400 \mathrm{MHz}\right)$ of $\mathbf{3 b}$

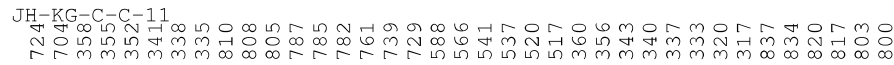<smiles>Cc1ccc2c(ccc3c2nc2ccccn23)c1</smiles>

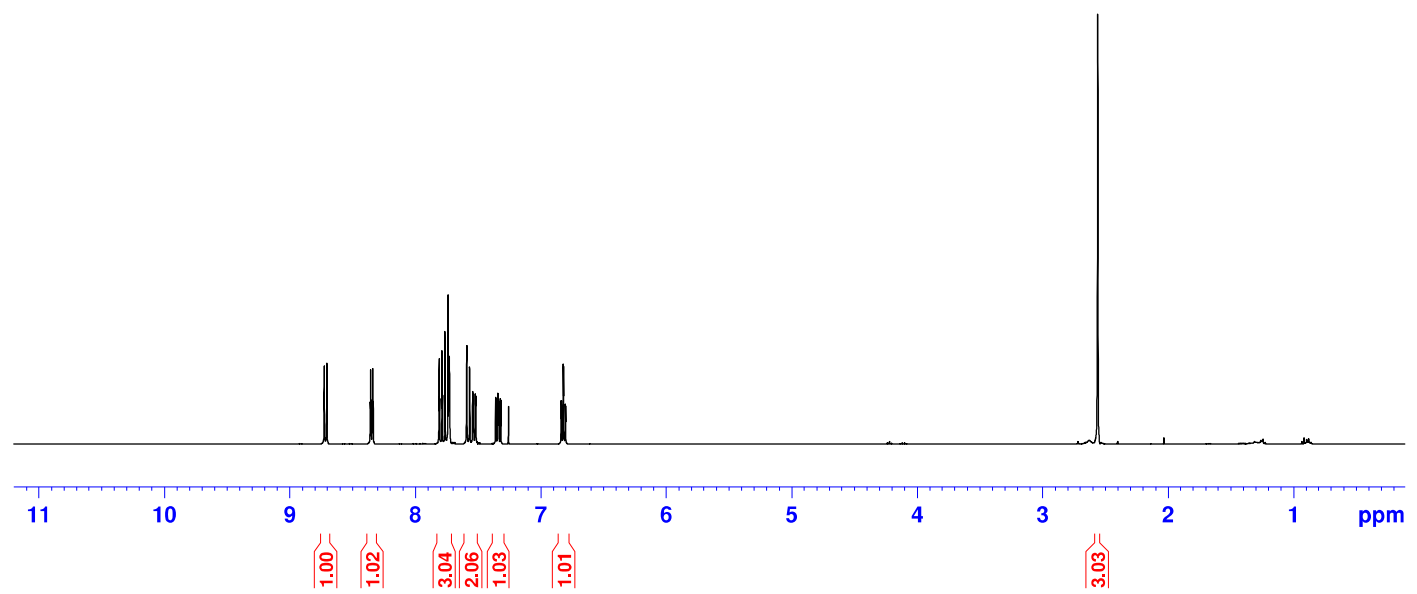

${ }^{13} \mathrm{C} \mathrm{NMR}\left(\mathrm{CDCl}_{3}, 100 \mathrm{MHz}\right)$ of $\mathbf{3 b}$

JH-KG-C-C-11

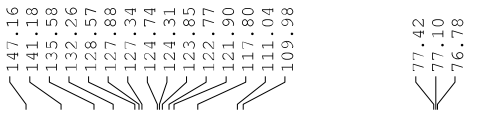

-

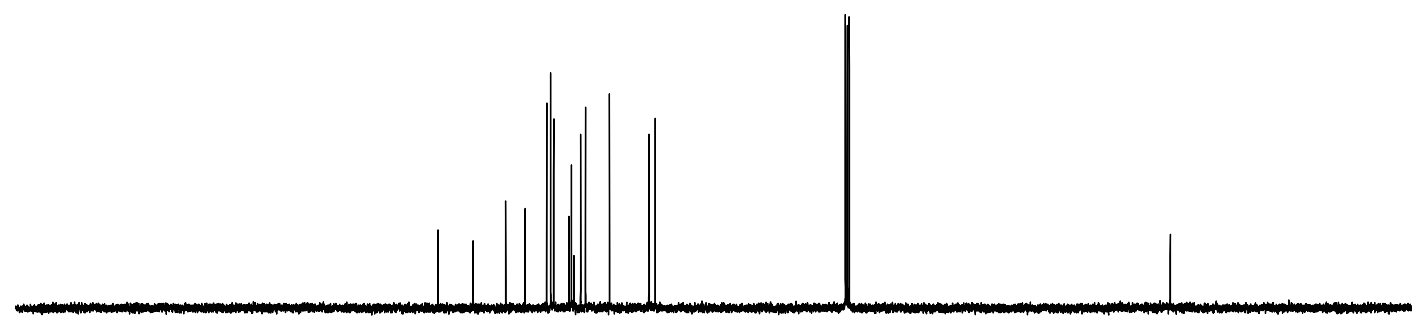

$\begin{array}{lllllllllllllllllllllll}210 & 200 & 190 & 180 & 170 & 160 & 150 & 140 & 130 & 120 & 110 & 100 & 90 & 80 & 70 & 60 & 50 & 40 & 30 & 20 & 10 & 0 & \mathrm{ppm}\end{array}$ 
${ }^{1} \mathrm{H} \mathrm{NMR}\left(\mathrm{CDCl}_{3}, 400 \mathrm{MHz}\right)$ of $\mathbf{3 c}$

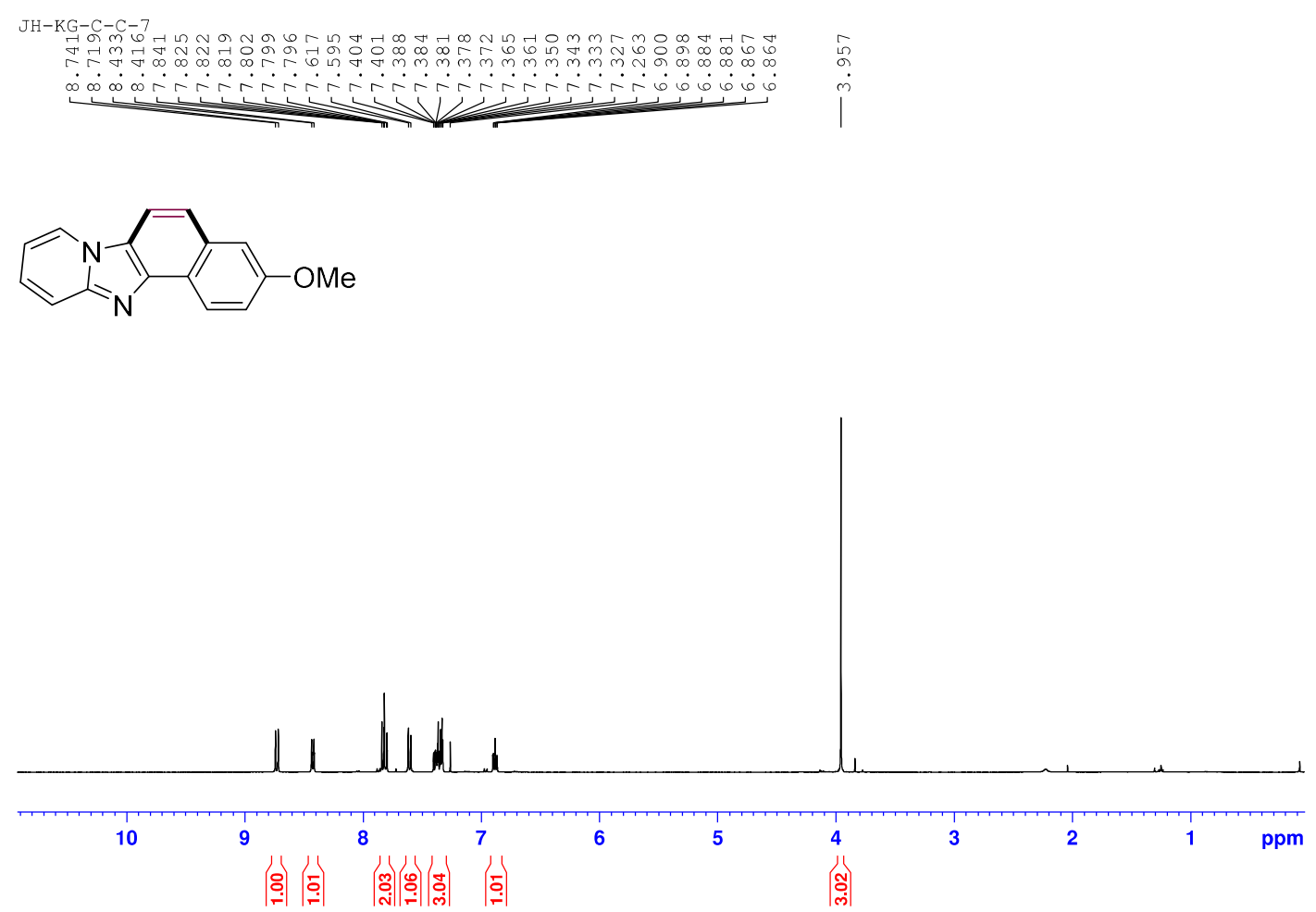

${ }^{13} \mathrm{C} \mathrm{NMR}\left(\mathrm{CDCl}_{3}, 100 \mathrm{MHz}\right)$ of $\mathbf{3 c}$

$\mathrm{JH}-\mathrm{KG}-\mathrm{C}-\mathrm{C}-7$

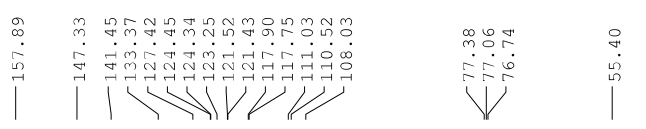

-

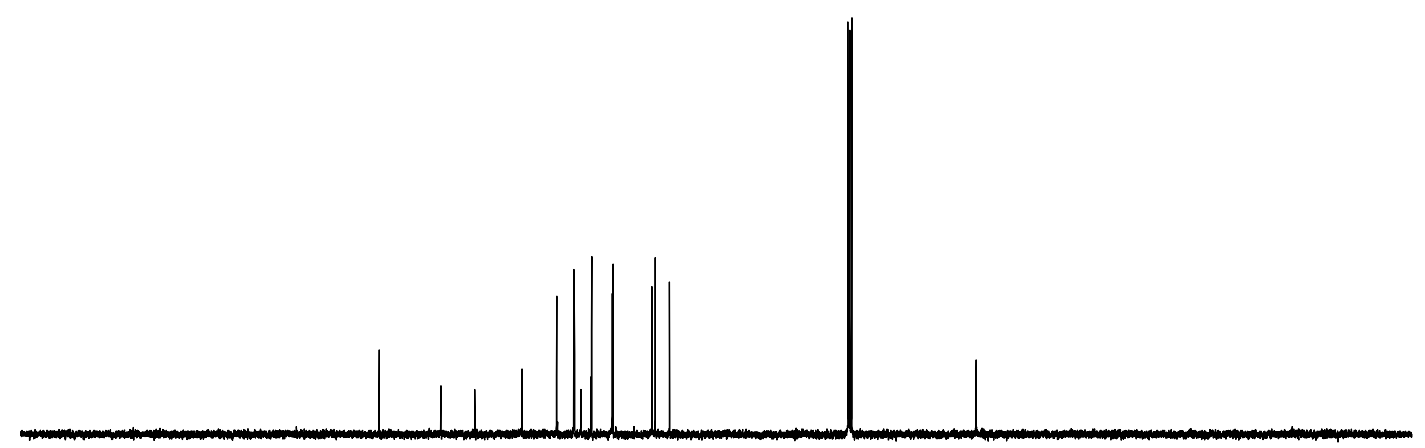

$\begin{array}{llllllllllllllllllllll}210 & 200 & 190 & 180 & 170 & 160 & 150 & 140 & 130 & 120 & 110 & 100 & 90 & 80 & 70 & 60 & 50 & 40 & 30 & 20 & 10 & 0\end{array}$ 
${ }^{1} \mathrm{H} \mathrm{NMR}\left(\mathrm{CDCl}_{3}, 400 \mathrm{MHz}\right)$ of $\mathbf{3 d}$

$\mathrm{JH}-\mathrm{KG}-\mathrm{C}-\mathrm{C}-6$

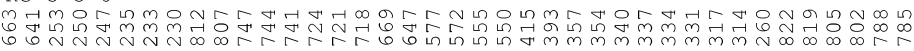

0

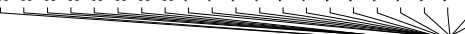<smiles>Clc1ccc2ccc3c(nc4ccccn43)c2c1</smiles>

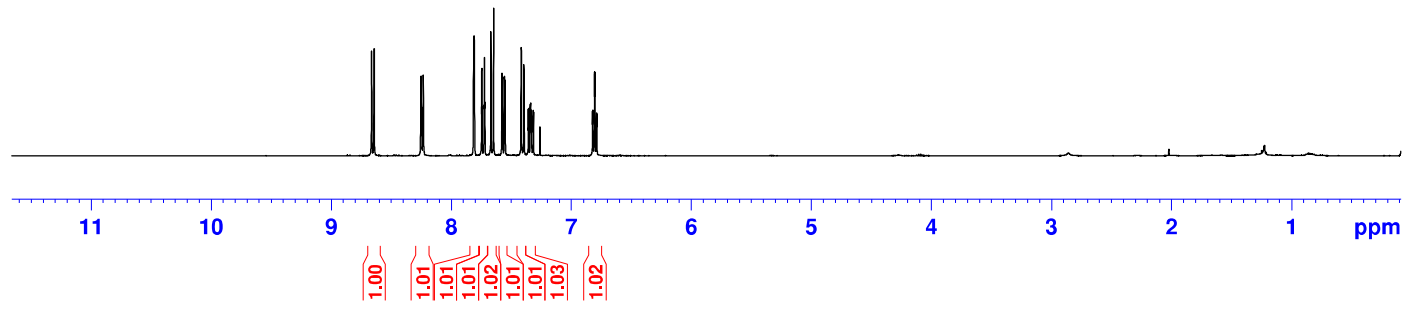

${ }^{13} \mathrm{C} \mathrm{NMR}\left(\mathrm{CDCl}_{3}, 100 \mathrm{MHz}\right)$ of $\mathbf{3 d}$

$\mathrm{JH}-\mathrm{KG}-\mathrm{C}-\mathrm{C}-6$

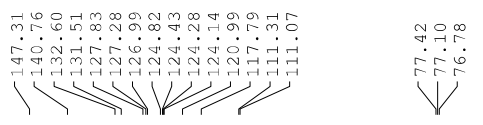

$\longrightarrow-C$

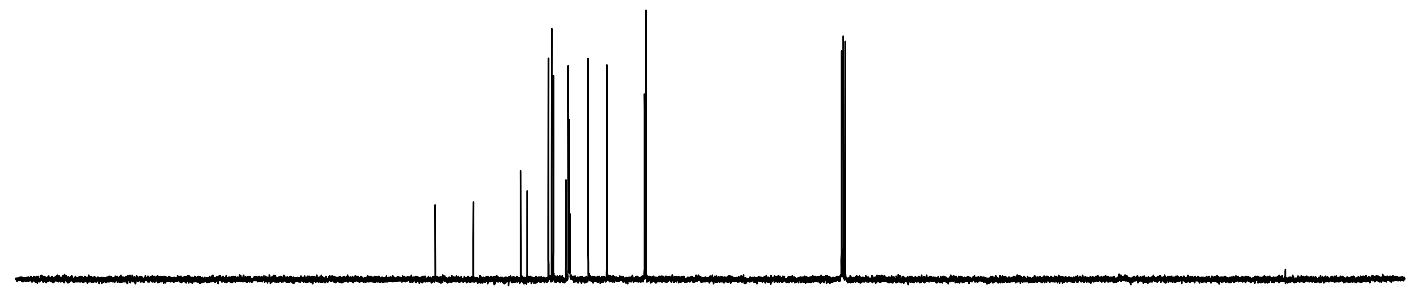

$\begin{array}{llllllllllllllllllllllll}210 & 200 & 190 & 180 & 170 & 160 & 150 & 140 & 130 & 120 & 110 & 100 & 90 & 80 & 70 & 60 & 50 & 40 & 30 & 20 & 10 & 0 & \mathrm{ppm}\end{array}$ 
${ }^{1} \mathrm{H} \mathrm{NMR}\left(\mathrm{CDCl}_{3}, 400 \mathrm{MHz}\right)$ of $\mathbf{3 e}$

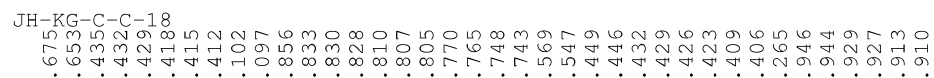

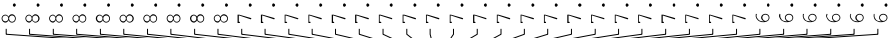<smiles>Brc1ccc2c(ccc3c2nc2ccccn23)c1</smiles>

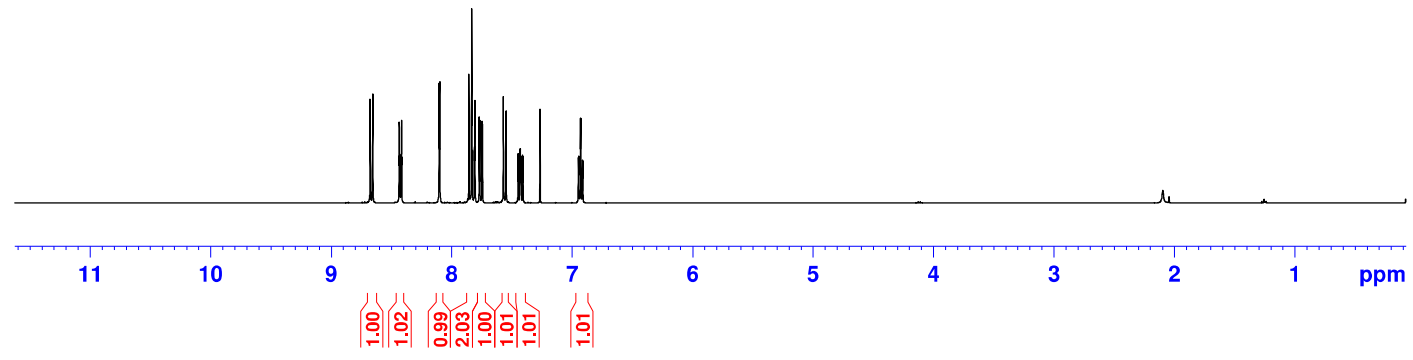

${ }^{13} \mathrm{C} \mathrm{NMR}\left(\mathrm{CDCl}_{3}, 100 \mathrm{MHz}\right)$ of $\mathbf{3 e}$

$\mathrm{JH}-\mathrm{KG}-\mathrm{C}-\mathrm{C}-18$

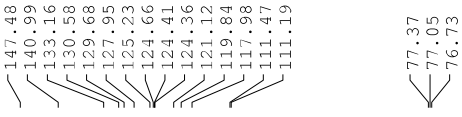

-

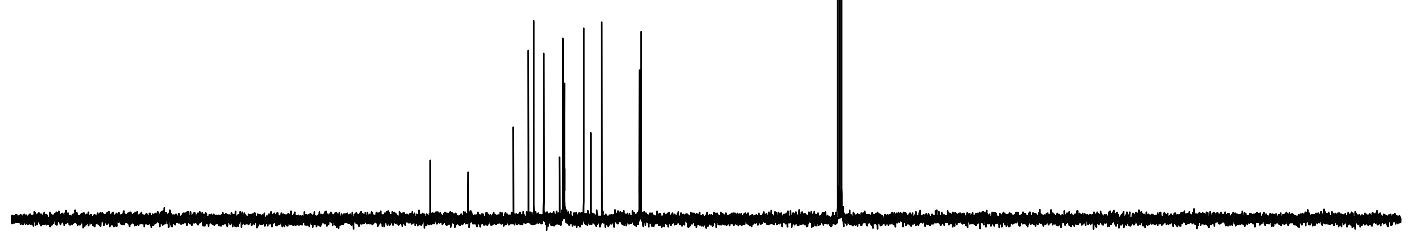

$\begin{array}{llllllllllllllllllllll}210 & 200 & 190 & 180 & 170 & 160 & 150 & 140 & 130 & 120 & 110 & 100 & 90 & 80 & 70 & 60 & 50 & 40 & 30 & 20 & 10 & 0\end{array}$ 
${ }^{1} \mathrm{H} \mathrm{NMR}\left(\mathrm{CDCl}_{3}, 400 \mathrm{MHz}\right)$ of $\mathbf{3 f}$

$\mathrm{JH}-\mathrm{KG}-\mathrm{C}-\mathrm{C}-5$

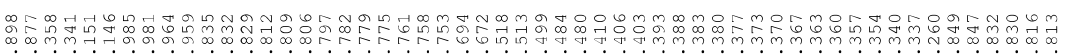

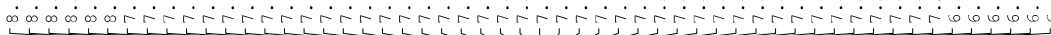

${ }_{N}^{N}$

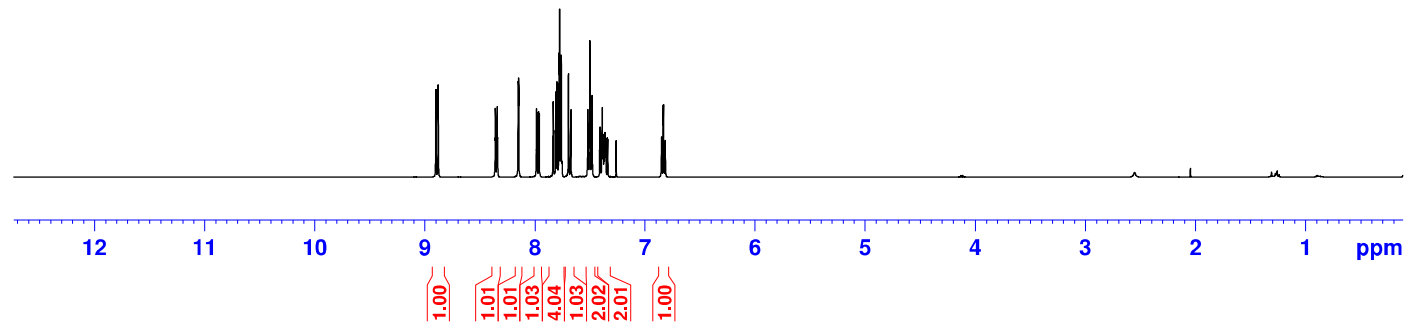

${ }^{13} \mathrm{C} \mathrm{NMR}\left(\mathrm{CDCl}_{3}, 100 \mathrm{MHz}\right)$ of $\mathbf{3 f}$

JH-KG-C-C-5

$\underbrace{\underbrace{}_{1}}$
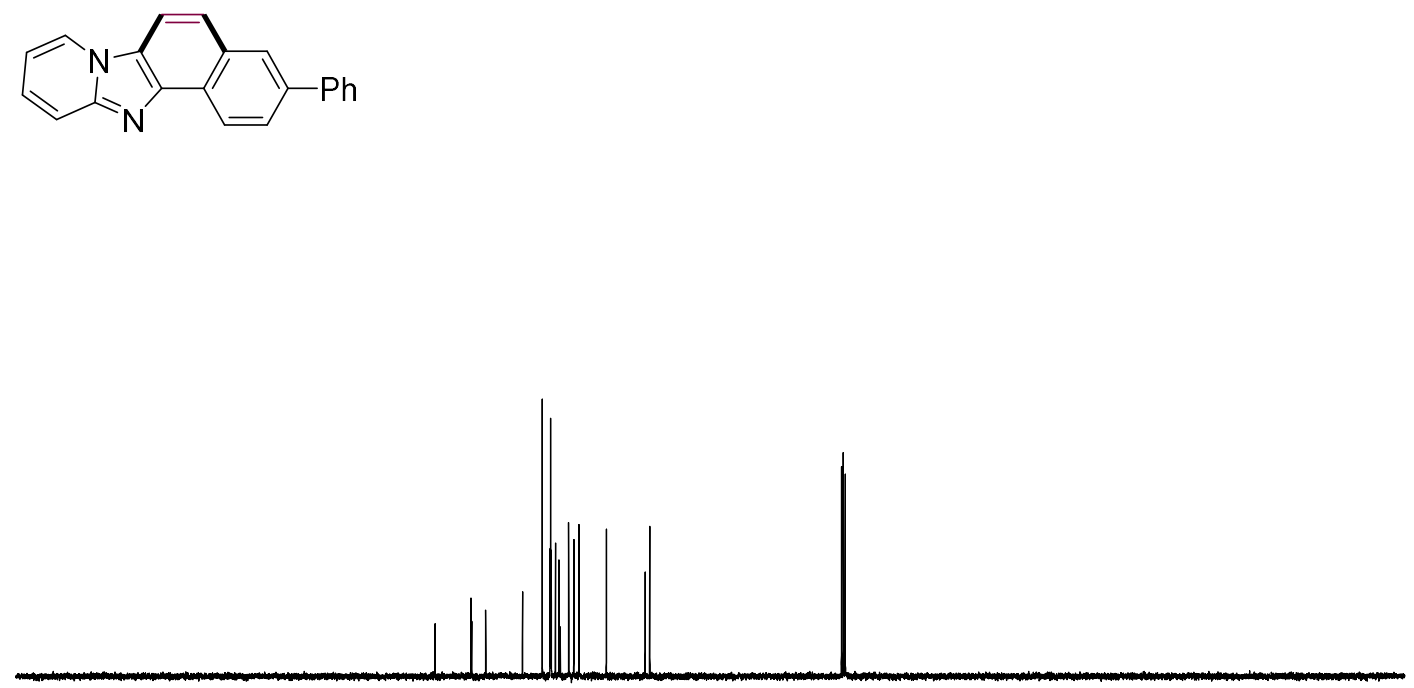

$\begin{array}{lllllllllllllllllllllll}210 & 200 & 190 & 180 & 170 & 160 & 150 & 140 & 130 & 120 & 110 & 100 & 90 & 80 & 70 & 60 & 50 & 40 & 30 & 20 & 10 & 0 & \mathrm{ppm}\end{array}$ 
${ }^{1} \mathrm{H} \mathrm{NMR}\left(\mathrm{CDCl}_{3}, 400 \mathrm{MHz}\right)$ of $\mathbf{3 g}$

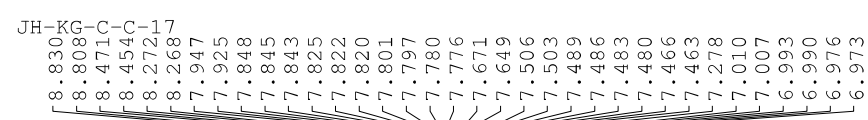<smiles>N#Cc1ccc2c(ccc3c2nc2ccccn23)c1</smiles>

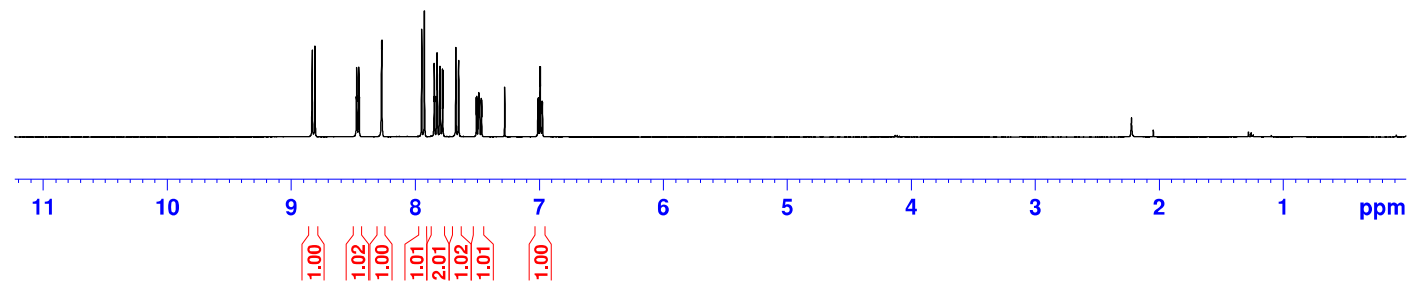

${ }^{13} \mathrm{C} \mathrm{NMR}\left(\mathrm{CDCl}_{3}, 100 \mathrm{MHz}\right)$ of $\mathbf{3 g}$

$\mathrm{JH}-\mathrm{KG}-\mathrm{C}-\mathrm{C}-17$

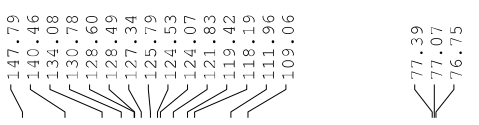

$\longrightarrow-C N$

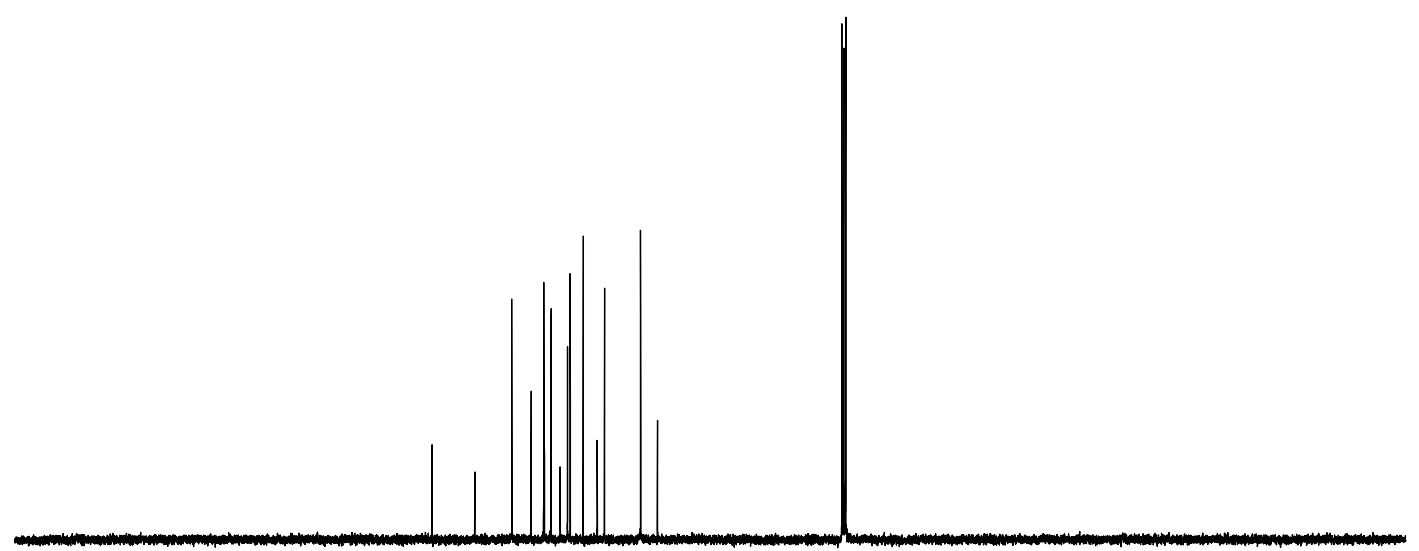

$\begin{array}{lllllllllllllllllllllll}210 & 200 & 190 & 180 & 170 & 160 & 150 & 140 & 130 & 120 & 110 & 100 & 90 & 80 & 70 & 60 & 50 & 40 & 30 & 20 & 10 & 0 & \mathrm{ppm}\end{array}$ 
${ }^{1} \mathrm{H} \mathrm{NMR}\left(\mathrm{CDCl}_{3}, 400 \mathrm{MHz}\right)$ of $\mathbf{3 h}$

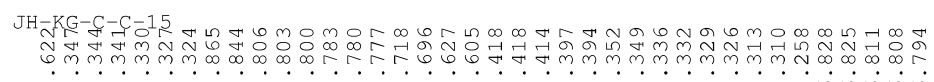

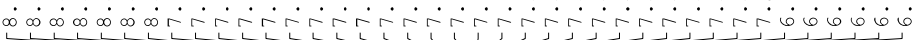

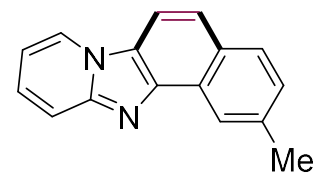

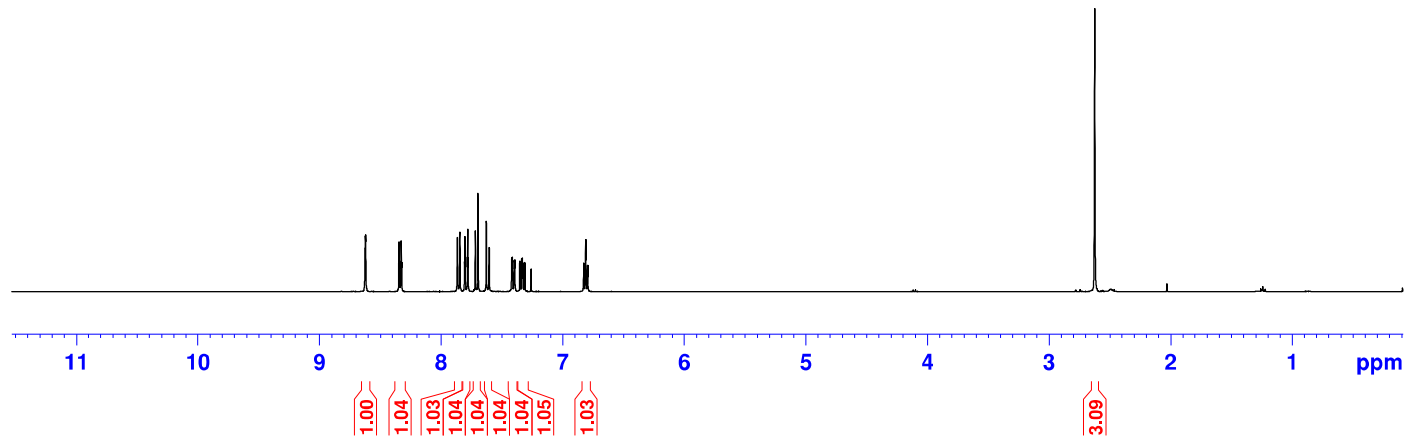

${ }^{13} \mathrm{C} \mathrm{NMR}\left(\mathrm{CDCl}_{3}, 100 \mathrm{MHz}\right)$ of $\mathbf{3 h}$

$\mathrm{JH}-\mathrm{KG}-\mathrm{C}-\mathrm{C}-15$

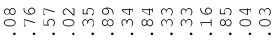

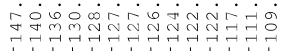

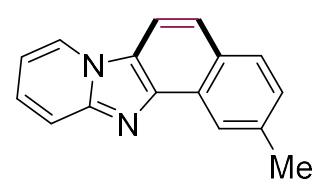

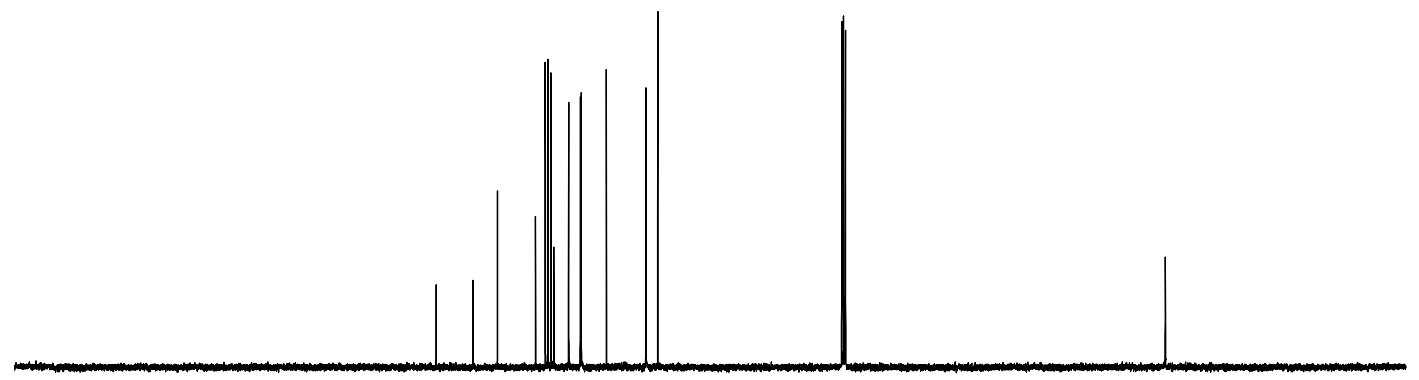

$\begin{array}{lllllllllllllllllllllll}210 & 200 & 190 & 180 & 170 & 160 & 150 & 140 & 130 & 120 & 110 & 100 & 90 & 80 & 70 & 60 & 50 & 40 & 30 & 20 & 10 & 0 & \mathrm{ppm}\end{array}$ 
${ }^{1} \mathrm{H} \mathrm{NMR}\left(\mathrm{CDCl}_{3}, 400 \mathrm{MHz}\right)$ of $\mathbf{3 i}$

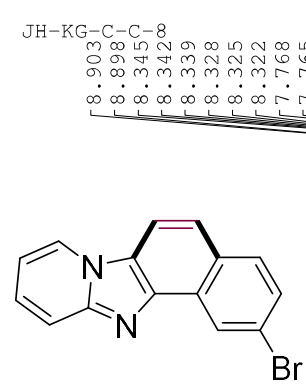

$\mathrm{Br}$

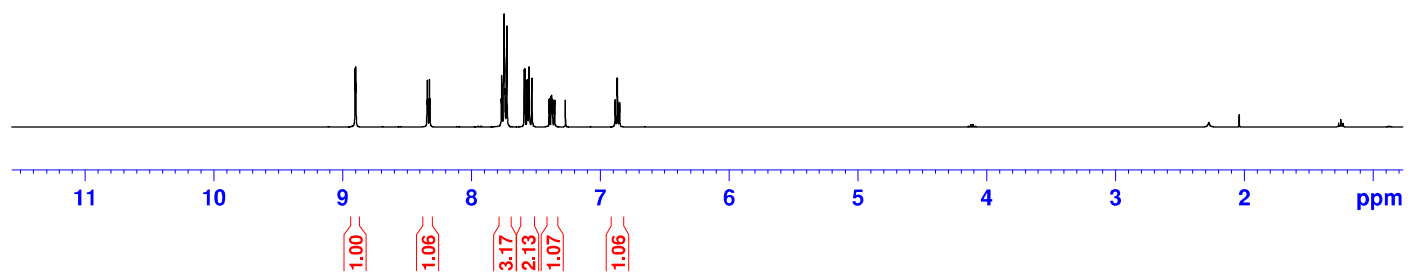

${ }^{13} \mathrm{C} \mathrm{NMR}\left(\mathrm{CDCl}_{3}, 100 \mathrm{MHz}\right)$ of $\mathbf{3 i}$

$\mathrm{JH}-\mathrm{KG}-\mathrm{C}-\mathrm{C}-8-2 \mathrm{nd}$

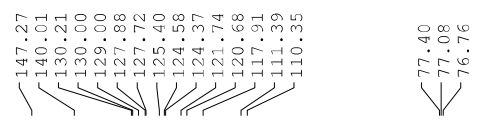

Br

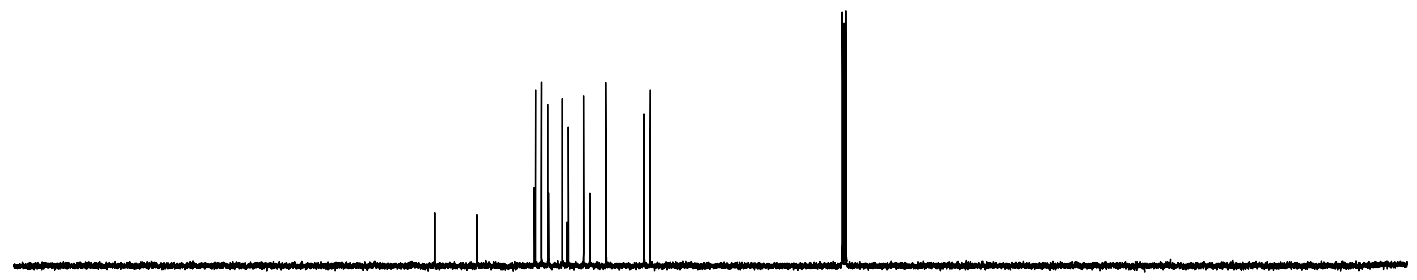

$\begin{array}{lllllllllllllllllllllll}210 & 200 & 190 & 180 & 170 & 160 & 150 & 140 & 130 & 120 & 110 & 100 & 90 & 80 & 70 & 60 & 50 & 40 & 30 & 20 & 10 & 0 & \mathrm{ppm}\end{array}$ 
${ }^{1} \mathrm{H} \mathrm{NMR}\left(\mathrm{CDCl}_{3}, 400 \mathrm{MHz}\right)$ of $\mathbf{3 j}$
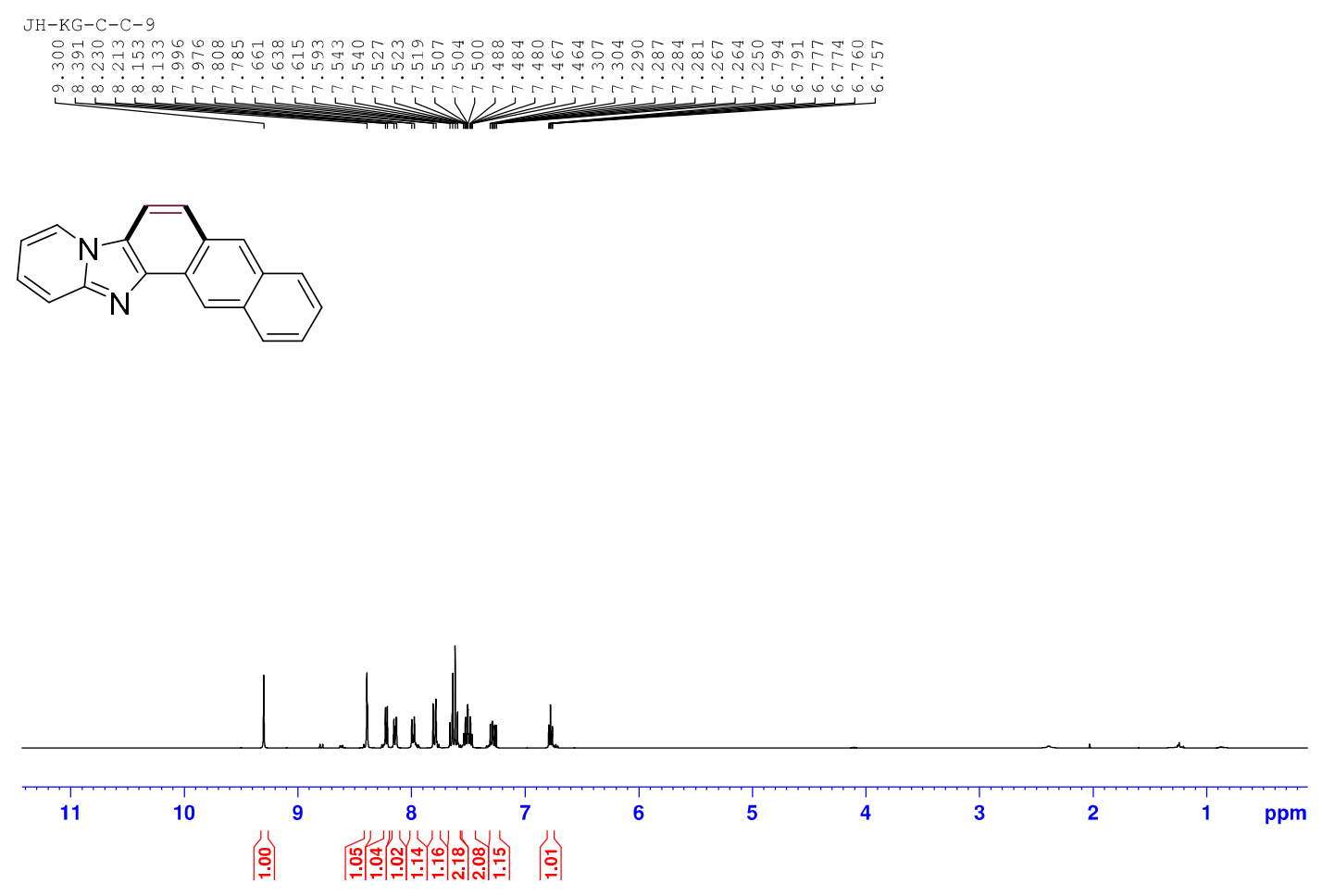

${ }^{13} \mathrm{C} \mathrm{NMR}\left(\mathrm{CDCl}_{3}, 100 \mathrm{MHz}\right)$ of $\mathbf{3 j}$

$\mathrm{JH}-\mathrm{KG}-\mathrm{C}-\mathrm{C}-9$
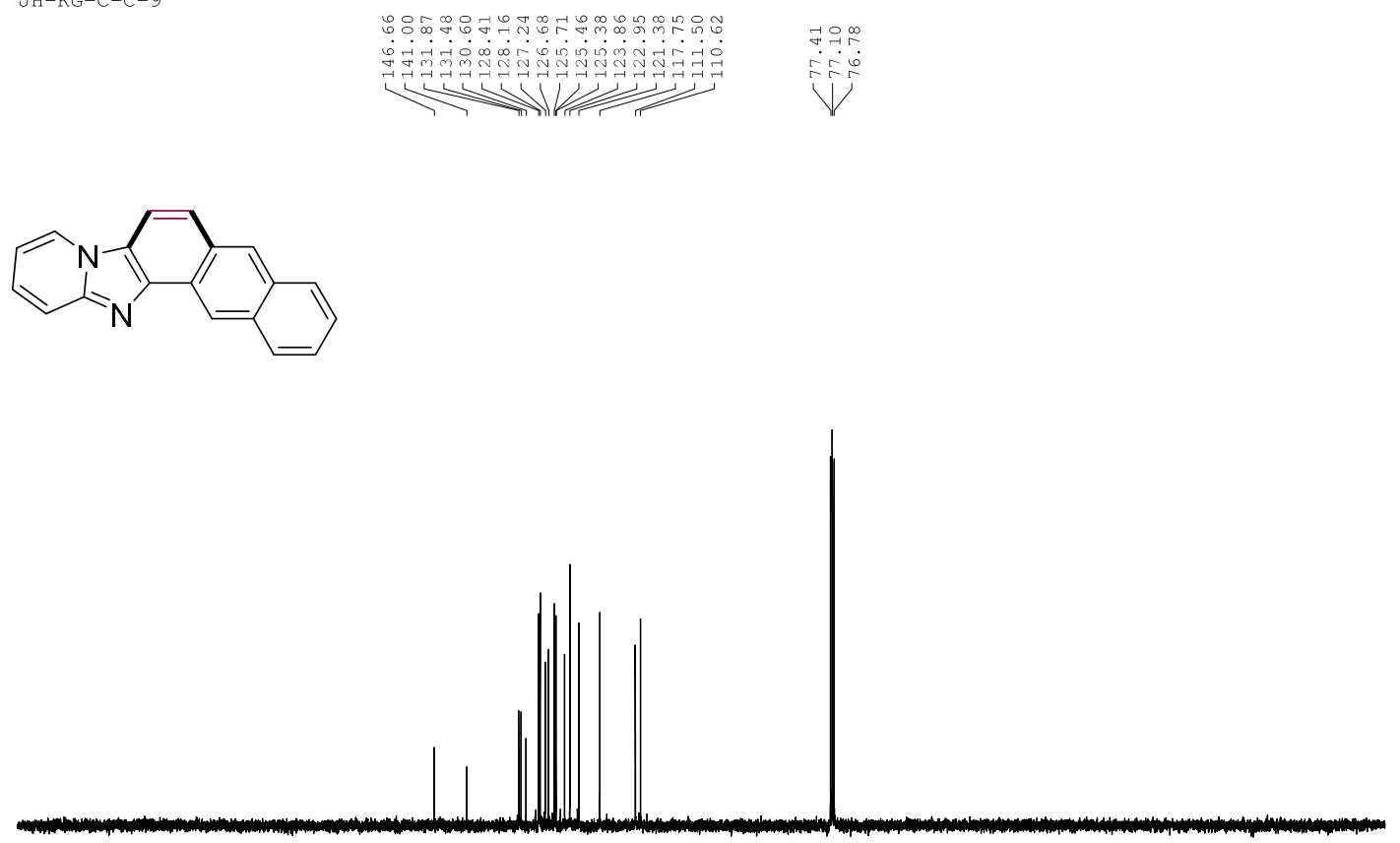

$\begin{array}{lllllllllllllllllllllll}210 & 200 & 190 & 180 & 170 & 160 & 150 & 140 & 130 & 120 & 110 & 100 & 90 & 80 & 70 & 60 & 50 & 40 & 30 & 20 & 10 & 0 & \mathrm{ppm}\end{array}$ 
${ }^{1} \mathrm{H} \mathrm{NMR}\left(\mathrm{CDCl}_{3}, 400 \mathrm{MHz}\right)$ of $\mathbf{3 k}$

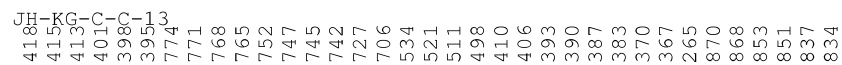

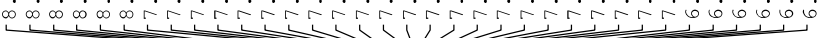
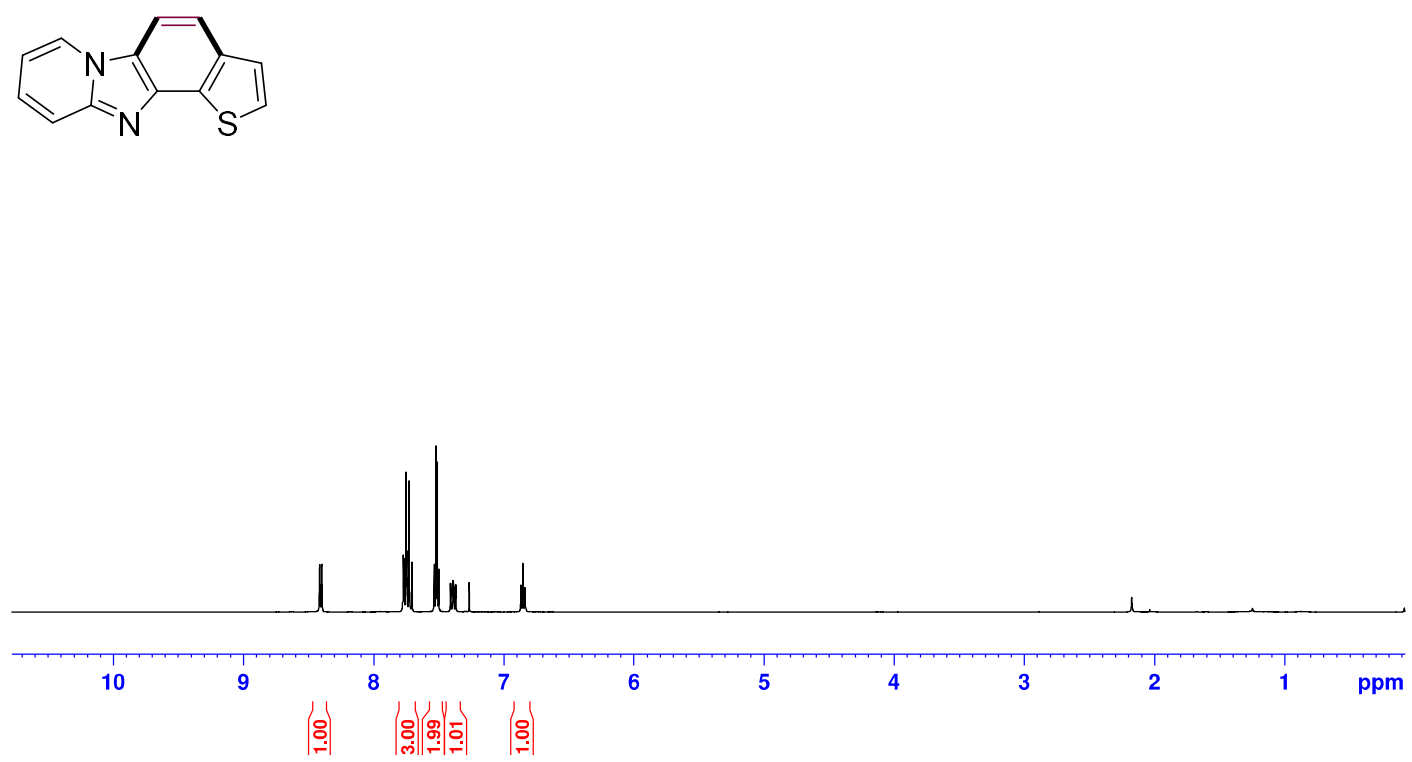

${ }^{13} \mathrm{C} \mathrm{NMR}\left(\mathrm{CDCl}_{3}, 100 \mathrm{MHz}\right)$ of $\mathbf{3 k}$

$\mathrm{JH}-\mathrm{KG}-\mathrm{C}-\mathrm{C}-13$

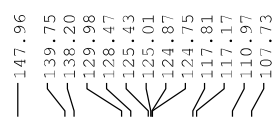

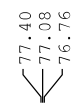

皮

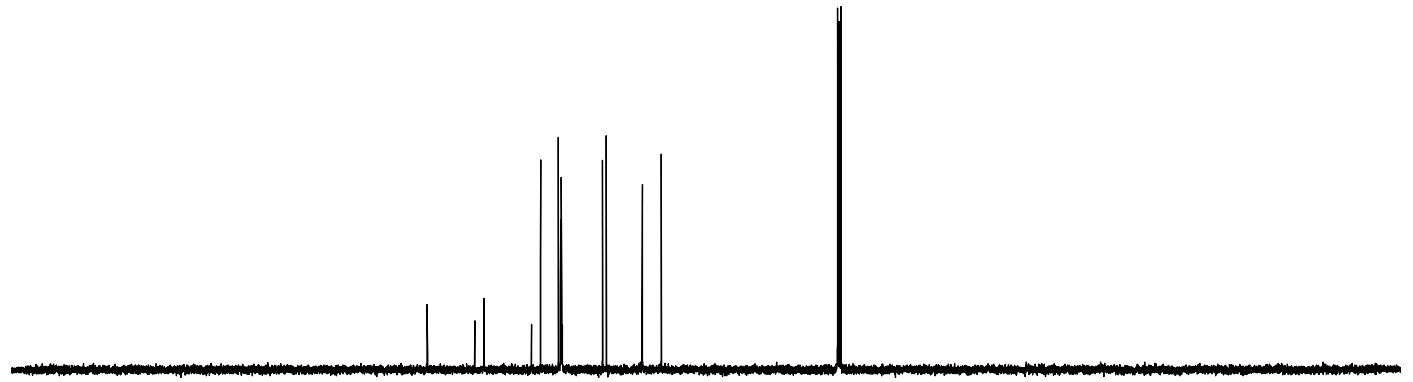

$\begin{array}{lllllllllllllllllllllll}210 & 200 & 190 & 180 & 170 & 160 & 150 & 140 & 130 & 120 & 110 & 100 & 90 & 80 & 70 & 60 & 50 & 40 & 30 & 20 & 10 & 0 & \mathrm{ppm}\end{array}$ 
${ }^{1} \mathrm{H} \mathrm{NMR}\left(\mathrm{CDCl}_{3}, 400 \mathrm{MHz}\right)$ of $\mathbf{3 l}$

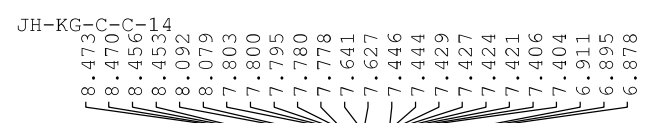

准

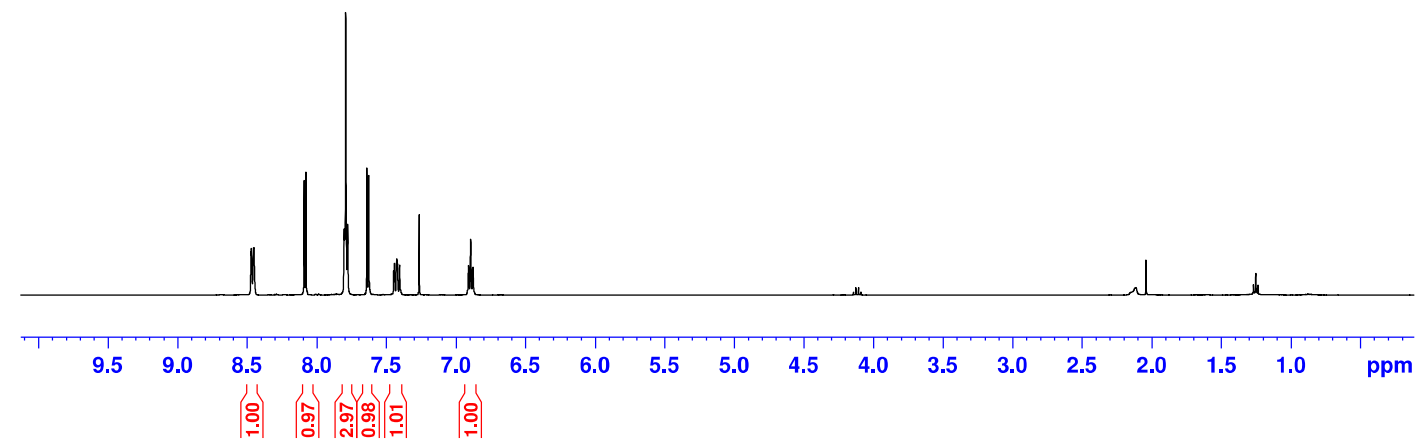

${ }^{13} \mathrm{C}$ NMR $\left(\mathrm{CDCl}_{3}, 100 \mathrm{MHz}\right)$ of $3 \mathrm{I}$

JH-KG-C-C-14

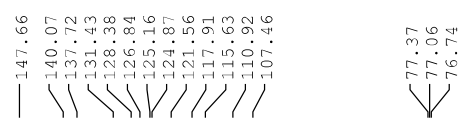

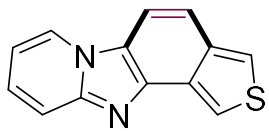

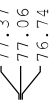

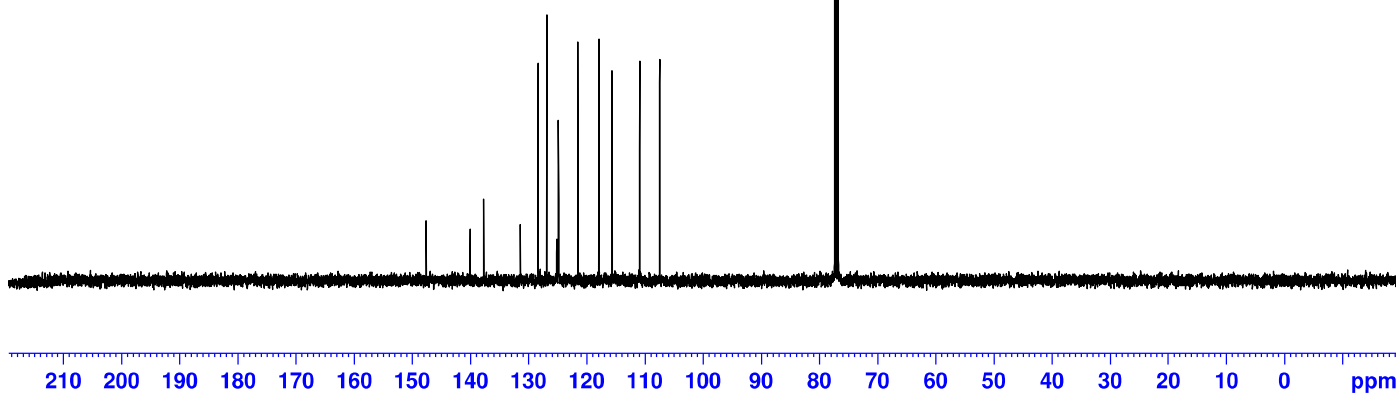


${ }^{1} \mathrm{H}$ NMR $\left(\mathrm{CDCl}_{3}, 400 \mathrm{MHz}\right)$ of $\mathbf{3 m}$

$\mathrm{JH}-\mathrm{KG}-\mathrm{C}-\mathrm{C}-5$

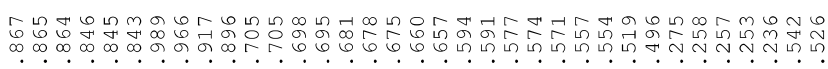

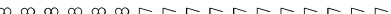<smiles></smiles>

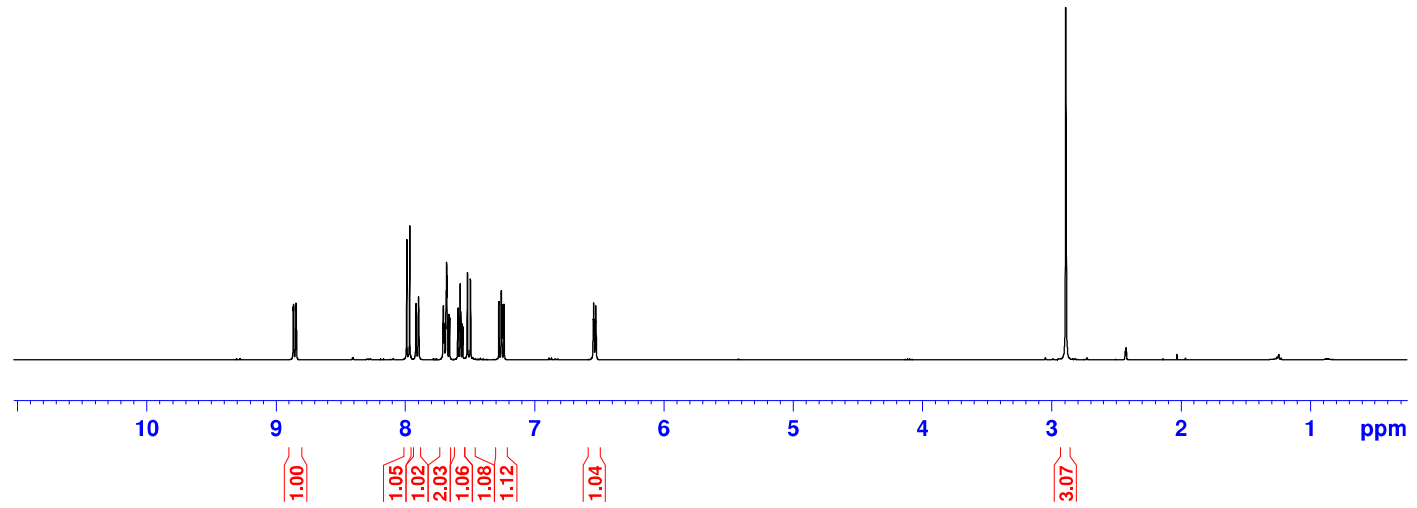

${ }^{13} \mathrm{C} \mathrm{NMR}\left(\mathrm{CDCl}_{3}, 100 \mathrm{MHz}\right)$ of $\mathbf{3 m}$

$\mathrm{JH}-\mathrm{KG}-\mathrm{C}-\mathrm{C}-5$

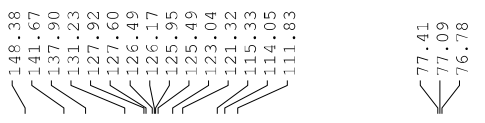

(l)

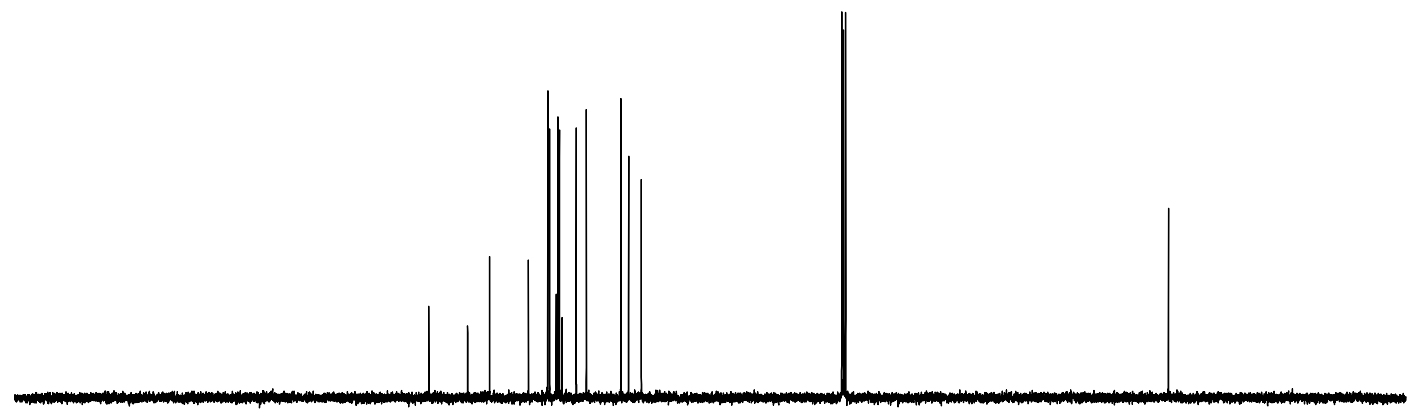

$\begin{array}{lllllllllllllllllllllll}210 & 200 & 190 & 180 & 170 & 160 & 150 & 140 & 130 & 120 & 110 & 100 & 90 & 80 & 70 & 60 & 50 & 40 & 30 & 20 & 10 & 0 & \mathrm{ppm}\end{array}$ 
${ }^{1} \mathrm{H} \mathrm{NMR}\left(\mathrm{CDCl}_{3}, 400 \mathrm{MHz}\right)$ of $\mathbf{3 n}$

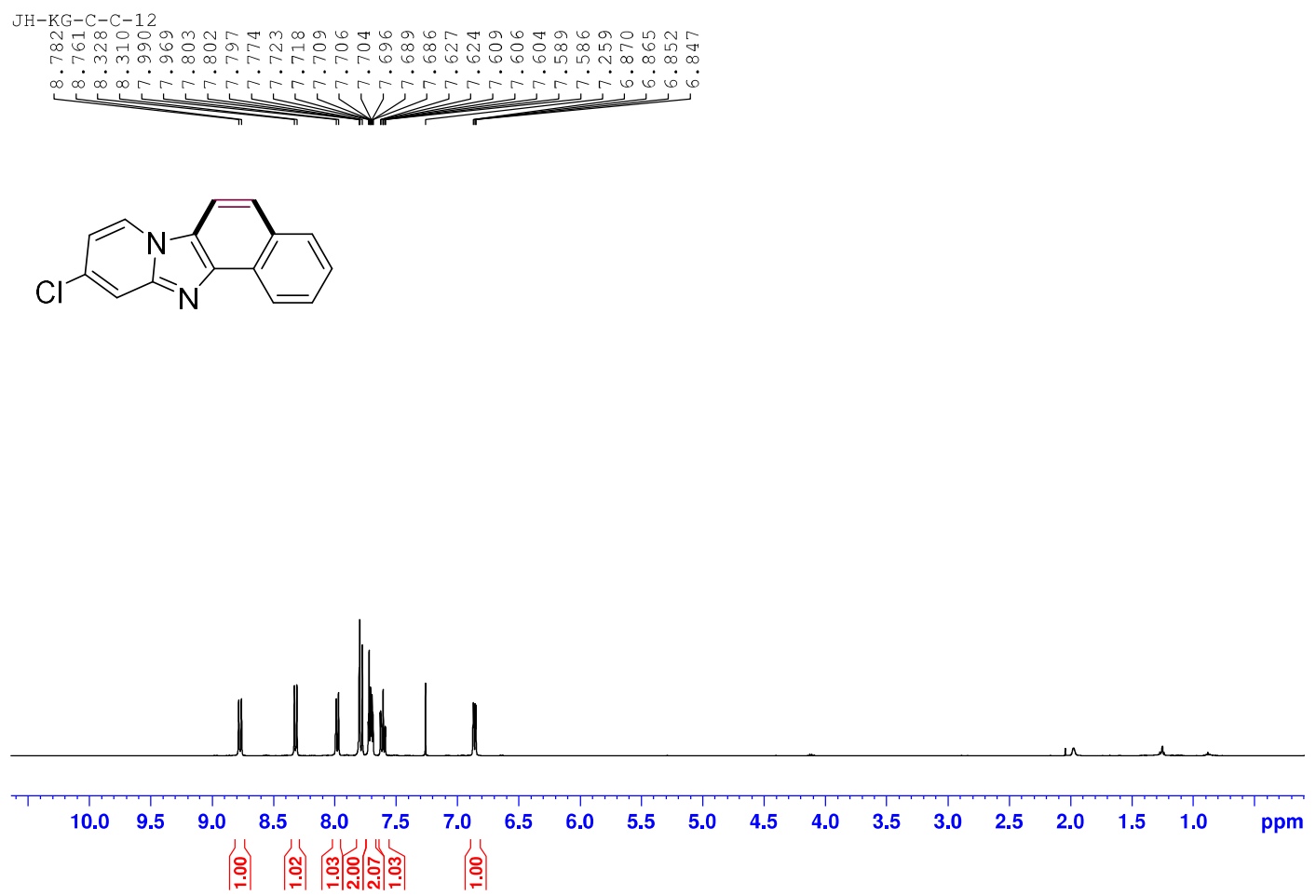

${ }^{13} \mathrm{C} \mathrm{NMR}\left(\mathrm{CDCl}_{3}, 100 \mathrm{MHz}\right)$ of $\mathbf{3 n}$

$\mathrm{JH}-\mathrm{KG}-\mathrm{C}-\mathrm{C}-12$

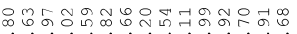

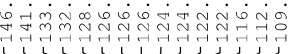

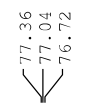

(l)

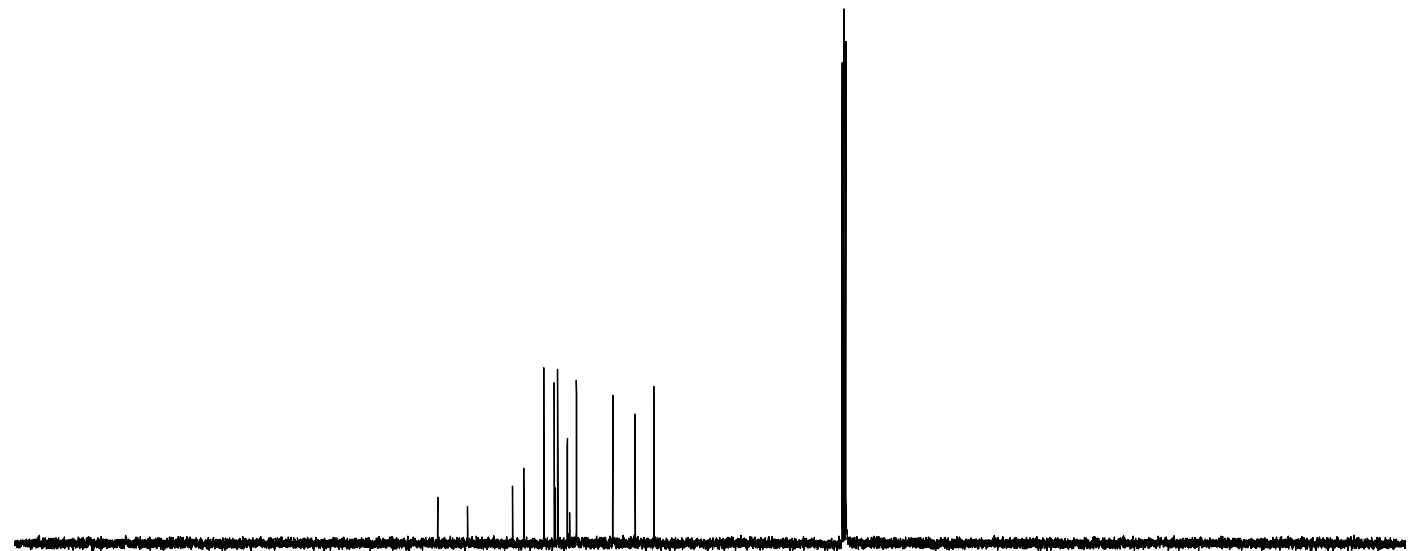

$\begin{array}{lllllllllllllllllllllll}210 & 200 & 190 & 180 & 170 & 160 & 150 & 140 & 130 & 120 & 110 & 100 & 90 & 80 & 70 & 60 & 50 & 40 & 30 & 20 & 10 & 0 & \mathrm{ppm}\end{array}$ 
${ }^{1} \mathrm{H} \mathrm{NMR}\left(\mathrm{CDCl}_{3}, 400 \mathrm{MHz}\right)$ of $\mathbf{3 o}$

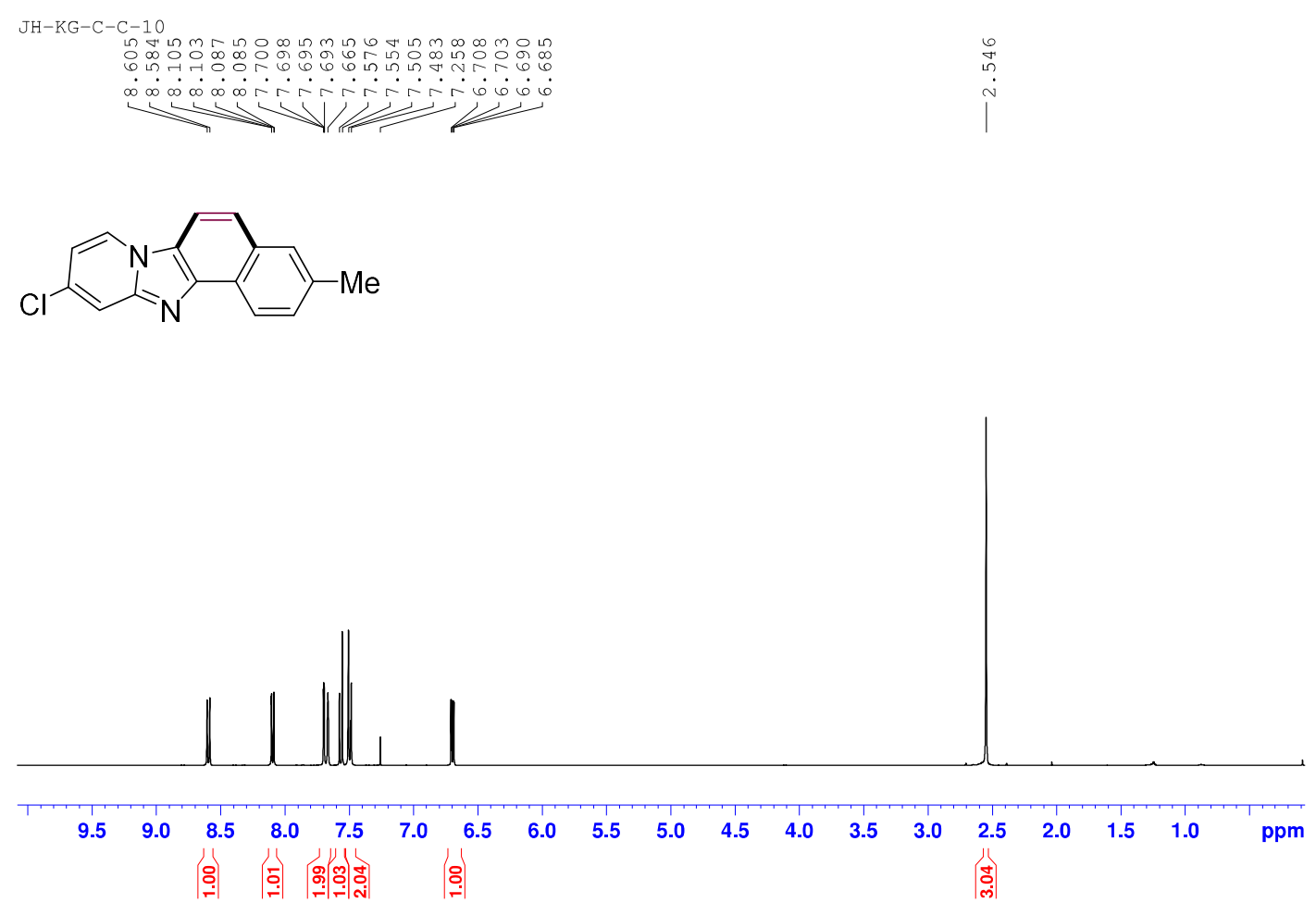

${ }^{13} \mathrm{C} \mathrm{NMR}\left(\mathrm{CDCl}_{3}, 100 \mathrm{MHz}\right)$ of $\mathbf{3 o}$

$\mathrm{JH}-\mathrm{KG}-\mathrm{C}-\mathrm{C}-10$

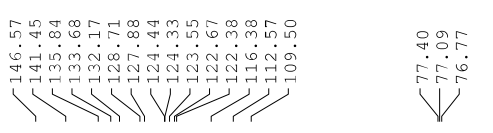

Me

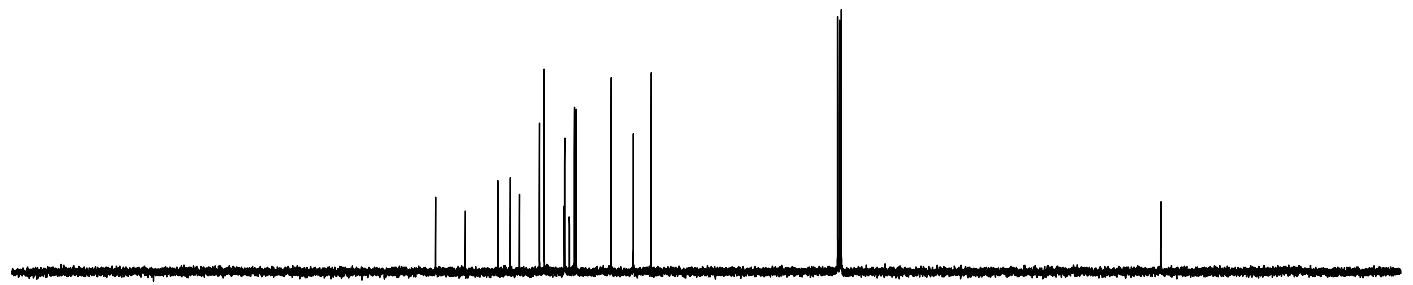

$\begin{array}{lllllllllllllllllllllll}210 & 200 & 190 & 180 & 170 & 160 & 150 & 140 & 130 & 120 & 110 & 100 & 90 & 80 & 70 & 60 & 50 & 40 & 30 & 20 & 10 & 0 & \mathrm{ppm}\end{array}$ 
${ }^{1} \mathrm{H} \mathrm{NMR}\left(\mathrm{CDCl}_{3}, 400 \mathrm{MHz}\right)$ of $\mathbf{3 p}$

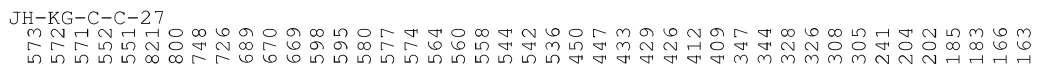

1

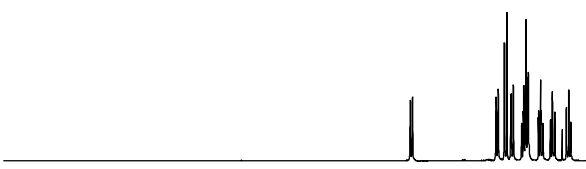

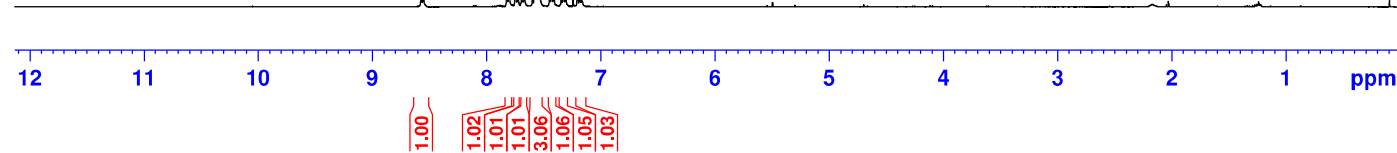

:

${ }^{13} \mathrm{C} \mathrm{NMR}\left(\mathrm{CDCl}_{3}, 100 \mathrm{MHz}\right)$ of $\mathbf{3 p}$

$\mathrm{JH}-\mathrm{KG}-\mathrm{C}-\mathrm{C}-27$

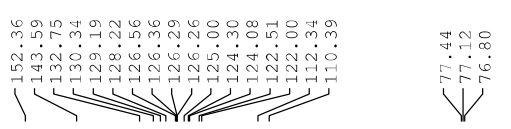

事

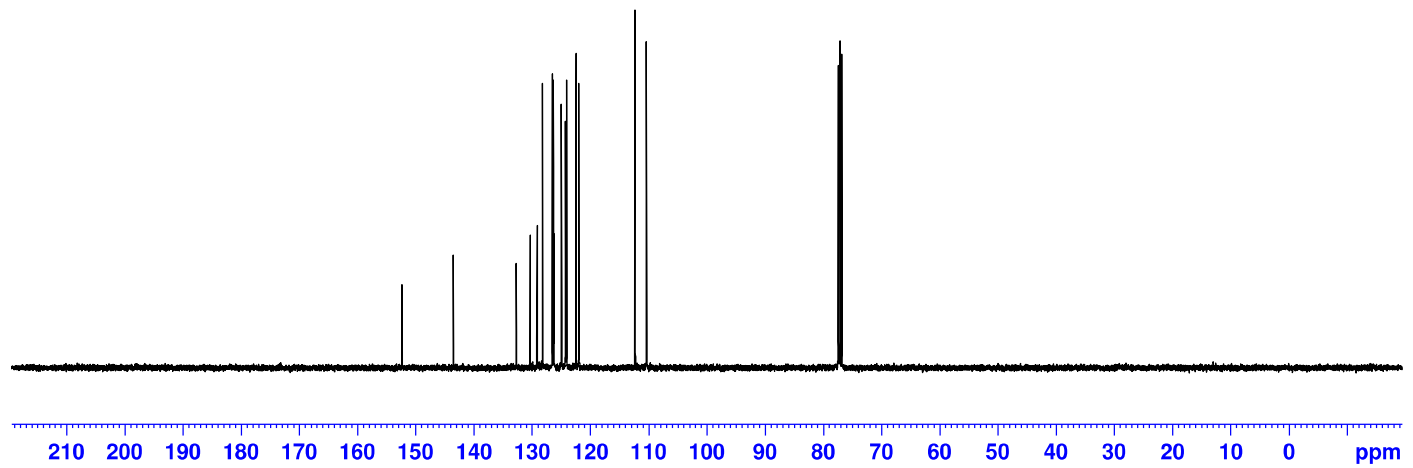


${ }^{1} \mathrm{H} \mathrm{NMR}\left(\mathrm{CDCl}_{3}, 400 \mathrm{MHz}\right)$ of $\mathbf{6 a}$

JH-KG-NSM-P-1

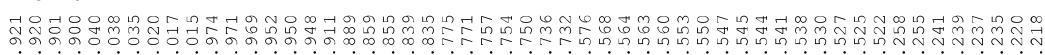

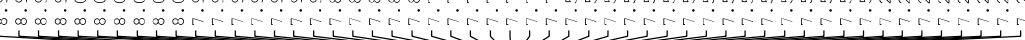
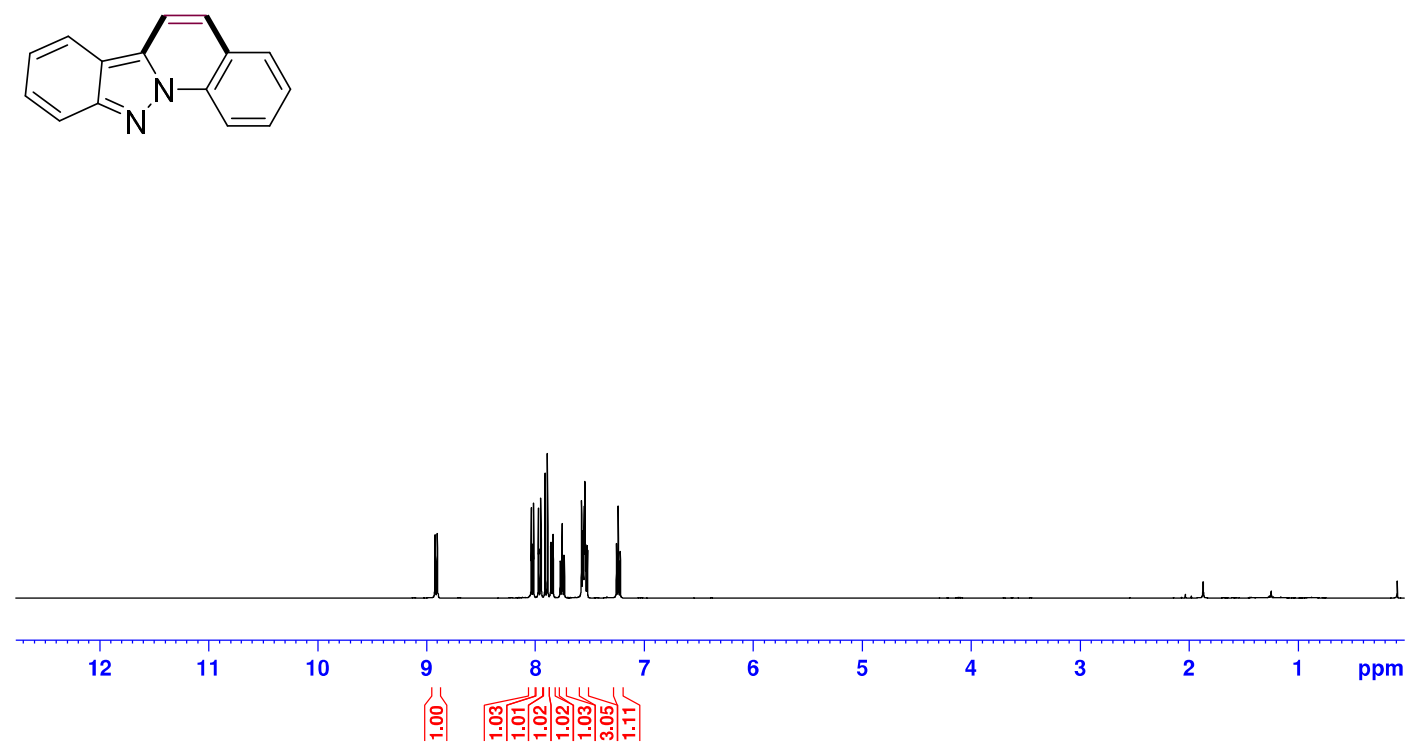

${ }^{13} \mathrm{C} \mathrm{NMR}\left(\mathrm{CDCl}_{3}, 100 \mathrm{MHz}\right)$ of $\mathbf{6 a}$

JH-KG-NSM-P-1

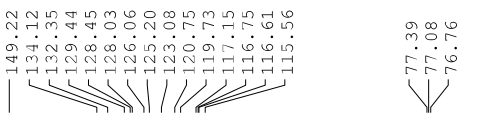

$\longrightarrow$

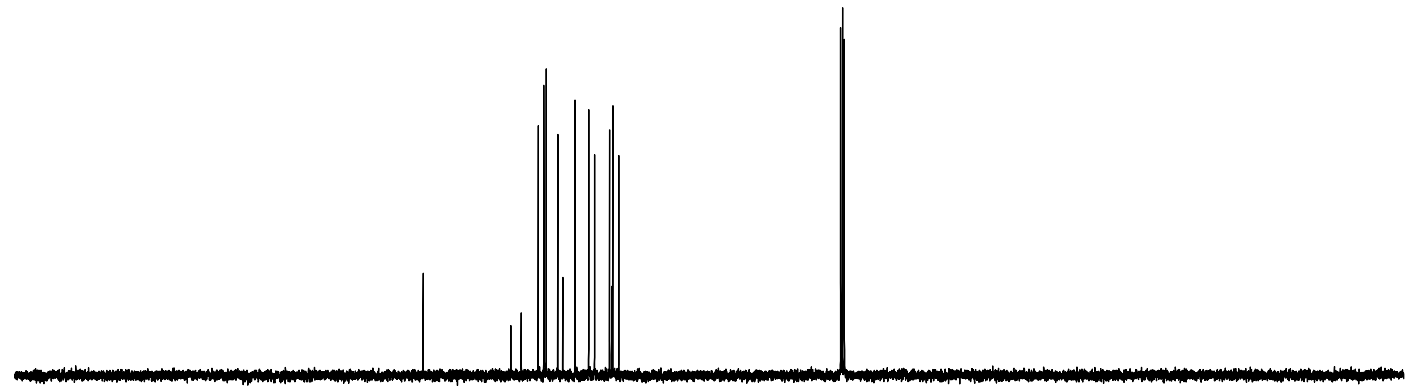

$\begin{array}{lllllllllllllllllllllll}210 & 200 & 190 & 180 & 170 & 160 & 150 & 140 & 130 & 120 & 110 & 100 & 90 & 80 & 70 & 60 & 50 & 40 & 30 & 20 & 10 & 0 & \mathrm{ppm}\end{array}$ 
${ }^{1} \mathrm{H} \mathrm{NMR}\left(\mathrm{CDCl}_{3}, 400 \mathrm{MHz}\right)$ of $\mathbf{6 b}$

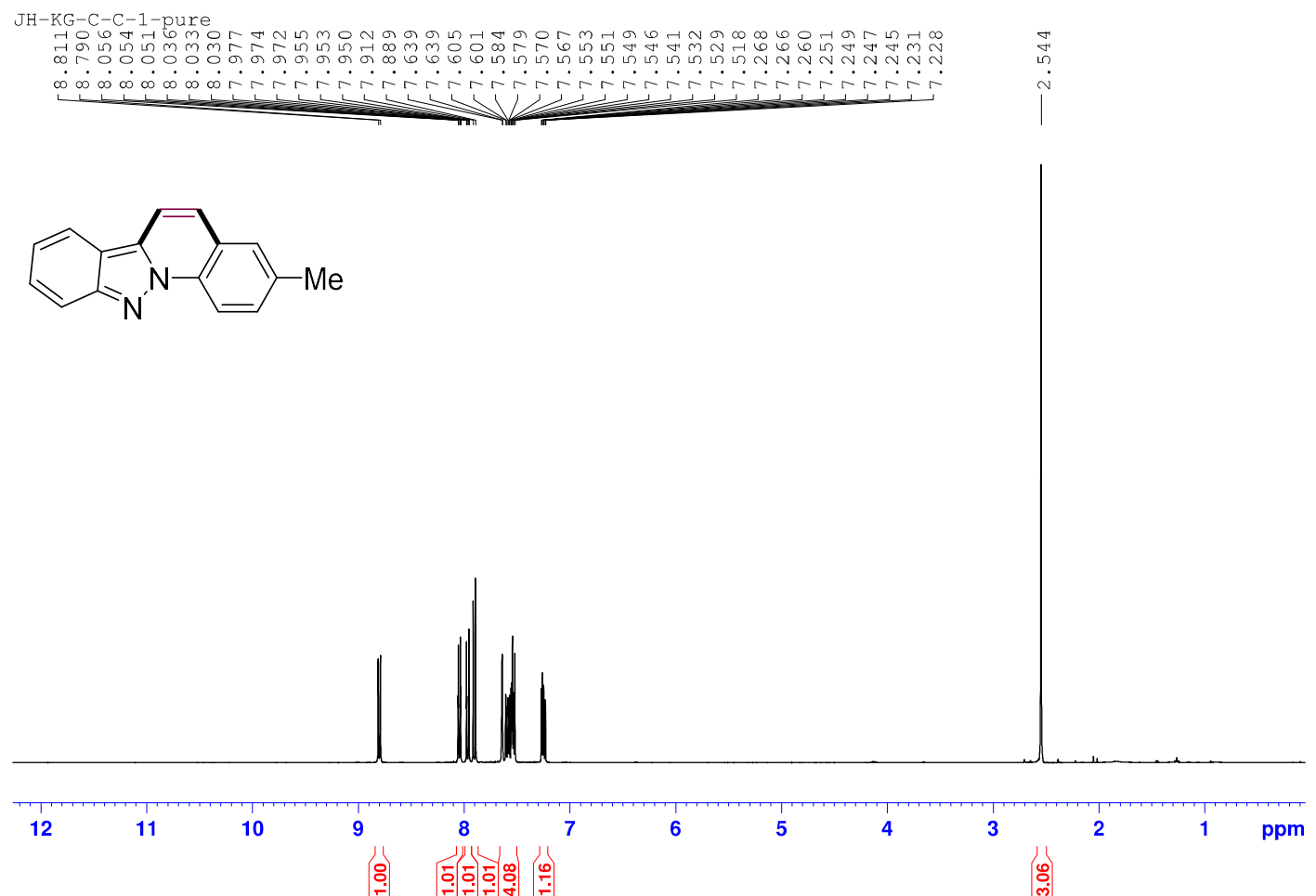

${ }^{13} \mathrm{C} \mathrm{NMR}\left(\mathrm{CDCl}_{3}, 100 \mathrm{MHz}\right)$ of $\mathbf{6 b}$

JH-KG-C-C-1-pure
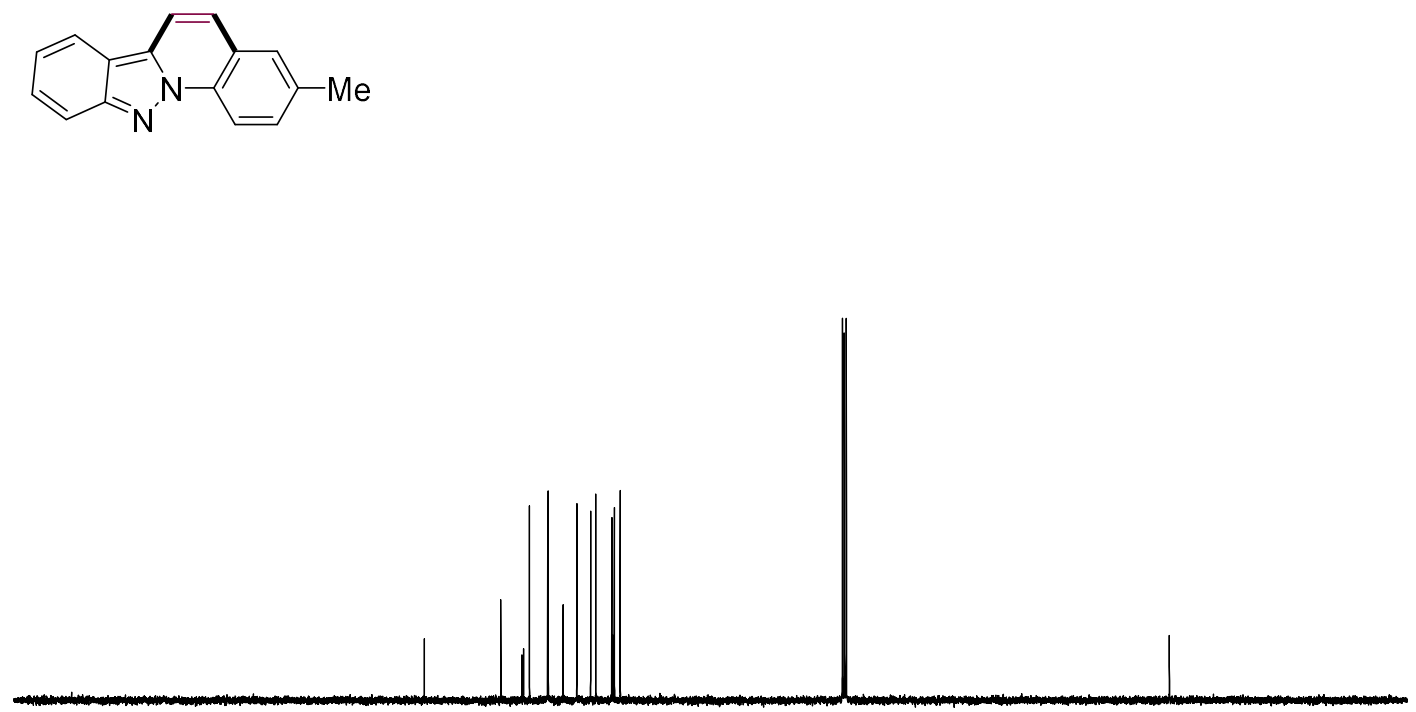

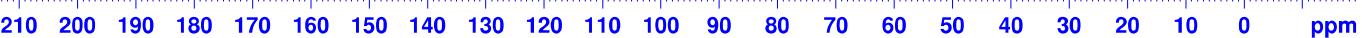


${ }^{1} \mathrm{H} \mathrm{NMR}\left(\mathrm{CDCl}_{3}, 400 \mathrm{MHz}\right)$ of $\mathbf{6 c}$

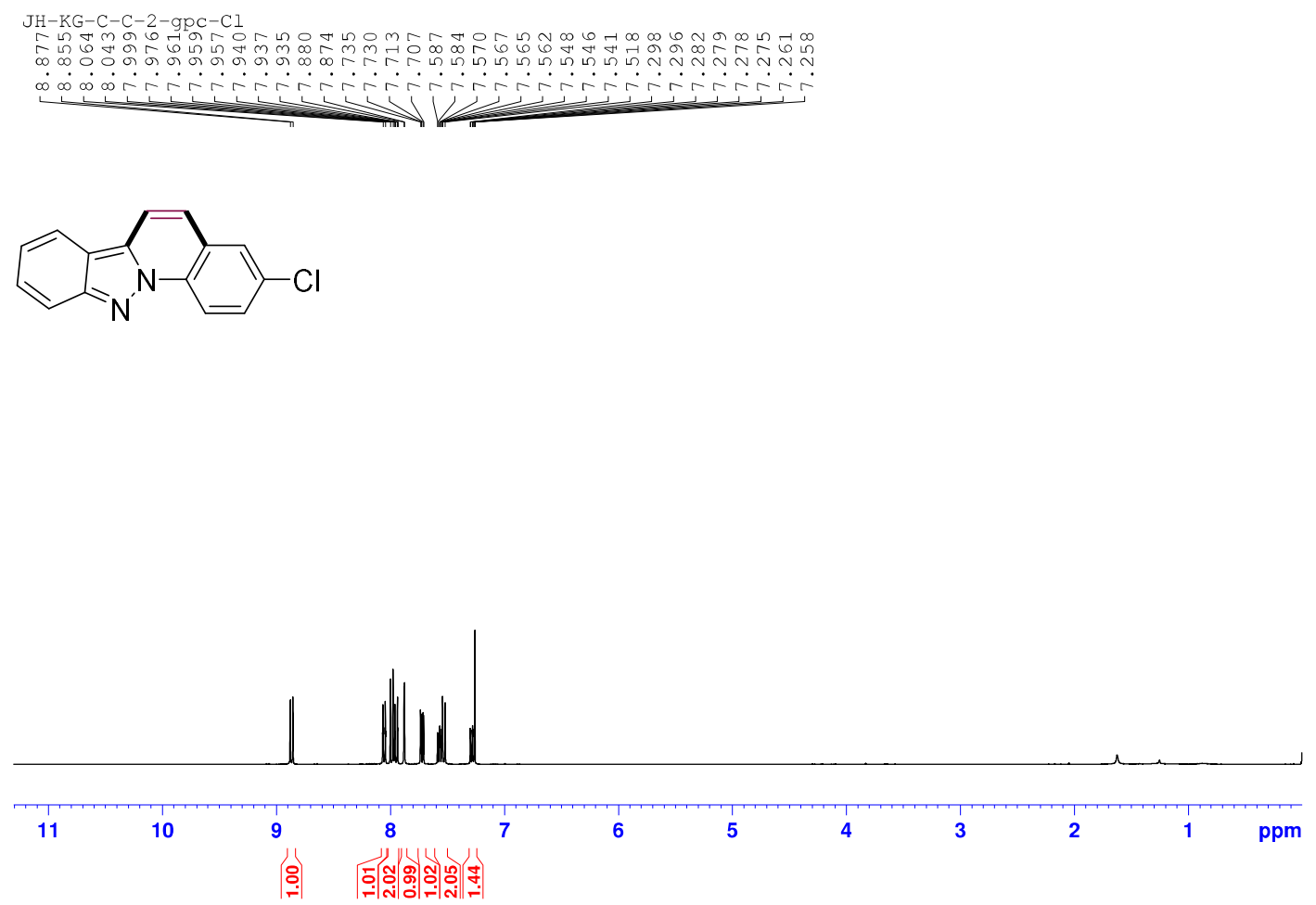

${ }^{13} \mathrm{C} \mathrm{NMR}\left(\mathrm{CDCl}_{3}, 100 \mathrm{MHz}\right)$ of $\mathbf{6 c}$

$\mathrm{JH}-\mathrm{KG}-\mathrm{C}-\mathrm{C}-2-\mathrm{gpC}-\mathrm{Cl}$

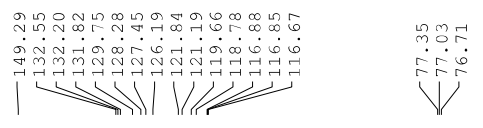

$C_{N}-C$

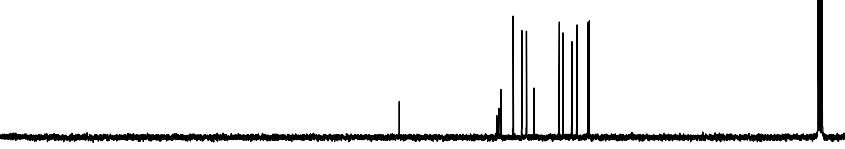

$\begin{array}{lllllllllllllllllllllll}210 & 200 & 190 & 180 & 170 & 160 & 150 & 140 & 130 & 120 & 110 & 100 & 90 & 80 & 70 & 60 & 50 & 40 & 30 & 20 & 10 & 0 & \mathrm{ppm}\end{array}$ 
${ }^{1} \mathrm{H} \mathrm{NMR}\left(\mathrm{CDCl}_{3}, 400 \mathrm{MHz}\right)$ of $\mathbf{6 d}$

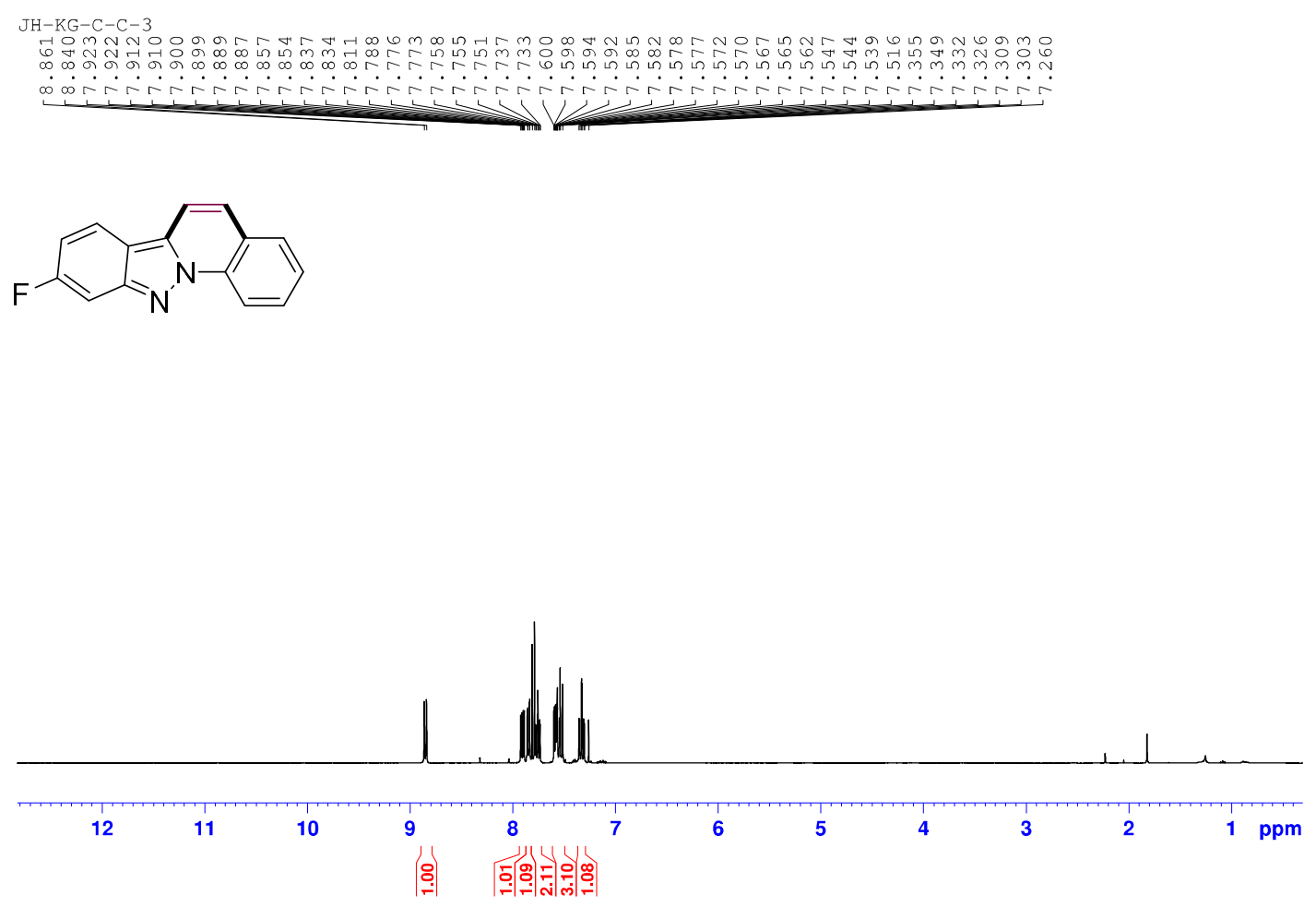

${ }^{13} \mathrm{C} \mathrm{NMR}\left(\mathrm{CDCl}_{3}, 100 \mathrm{MHz}\right)$ of $\mathbf{6 d}$

$\mathrm{JH}-\mathrm{KG}-\mathrm{C}-\mathrm{C}-3$

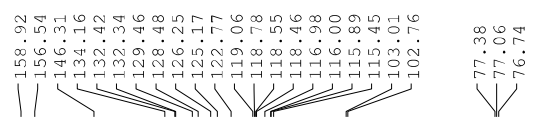

-

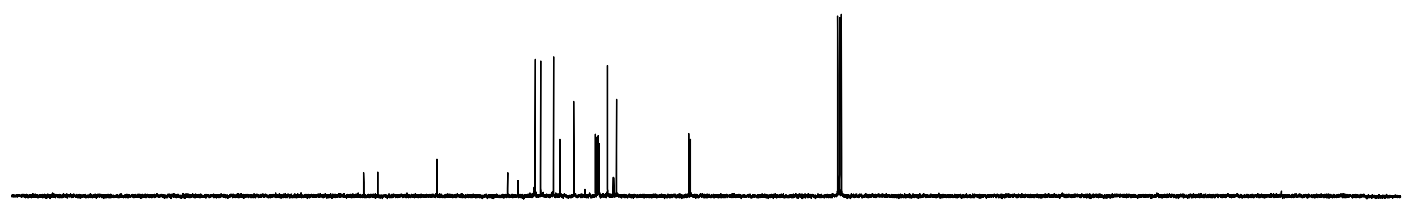

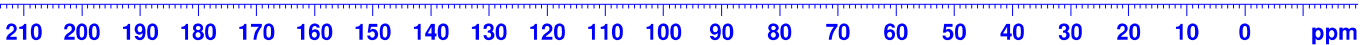


${ }^{19} \mathrm{~F} \mathrm{NMR}\left(\mathrm{CDCl}_{3}, 376 \mathrm{MHz}\right)$ of $\mathbf{6 d}$

$\mathrm{JH}-\mathrm{KG}-\mathrm{C}-\mathrm{C}-3$<smiles></smiles>

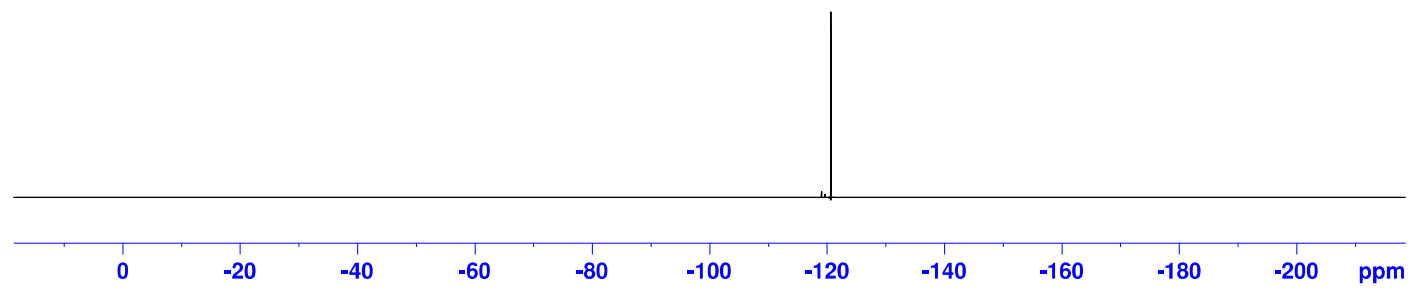


${ }^{1} \mathrm{H} \mathrm{NMR}\left(\mathrm{CDCl}_{3}, 400 \mathrm{MHz}\right)$ of $7 \mathbf{a}$

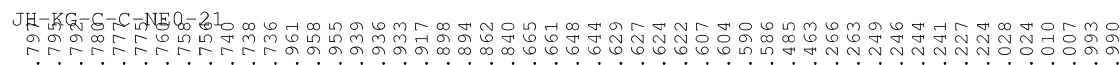

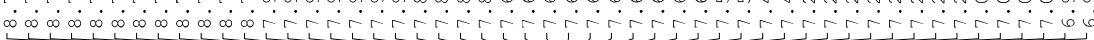

$\longrightarrow$

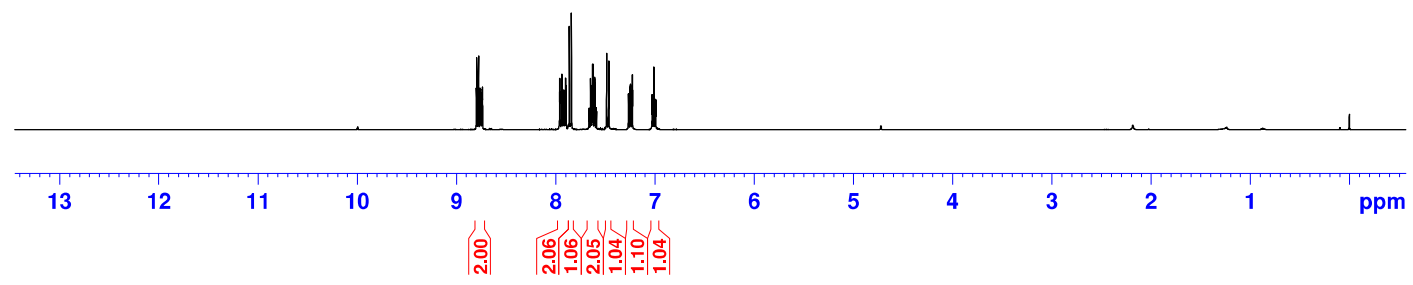

${ }^{13} \mathrm{C} \mathrm{NMR}\left(\mathrm{CDCl}_{3}, 100 \mathrm{MHz}\right)$ of $7 \mathbf{a}$

JH-KG-C-C-NE0-21

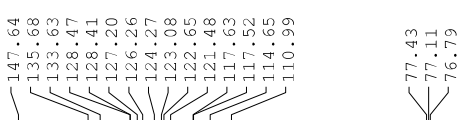

$\longrightarrow$

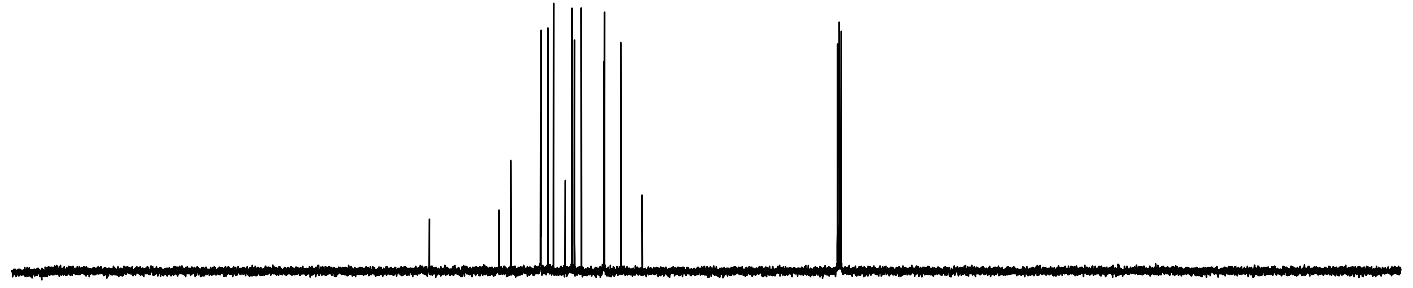

$\begin{array}{lllllllllllllllllllllll}210 & 200 & 190 & 180 & 170 & 160 & 150 & 140 & 130 & 120 & 110 & 100 & 90 & 80 & 70 & 60 & 50 & 40 & 30 & 20 & 10 & 0 & \mathrm{ppm}\end{array}$ 
${ }^{1} \mathrm{H} \mathrm{NMR}\left(\mathrm{CDCl}_{3}, 400 \mathrm{MHz}\right)$ of $7 \mathbf{b}$

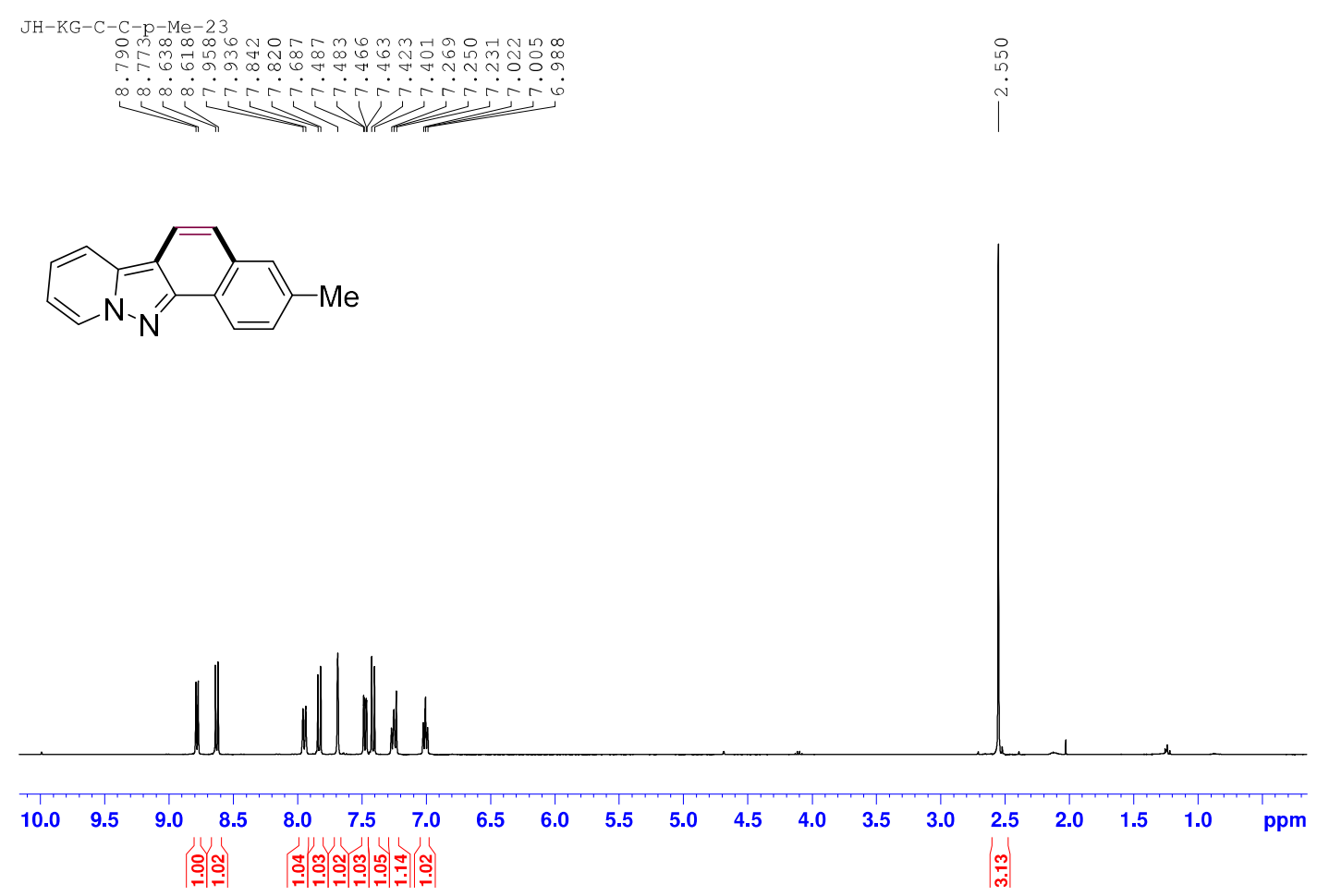

${ }^{13} \mathrm{C} \mathrm{NMR}\left(\mathrm{CDCl}_{3}, 100 \mathrm{MHz}\right)$ of $\mathbf{7 b}$

$\mathrm{JH}-\mathrm{KG}-\mathrm{C}-\mathrm{C}-\mathrm{p}-\mathrm{Me}-23$

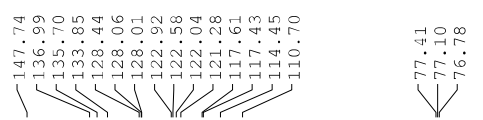

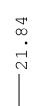<smiles>Cc1ccc2c(ccc3c2nn2ccccc32)c1</smiles>

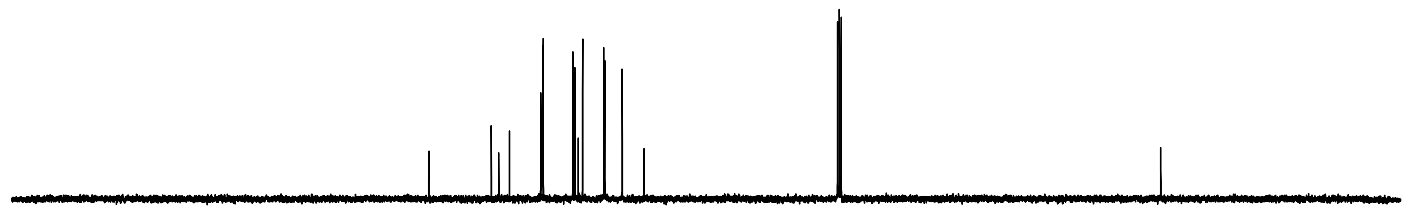

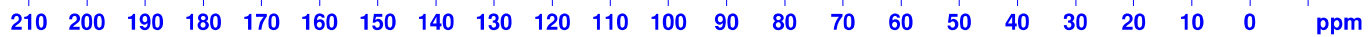


${ }^{1} \mathrm{H} \mathrm{NMR}\left(\mathrm{CDCl}_{3}, 400 \mathrm{MHz}\right)$ of $7 \mathbf{c}$

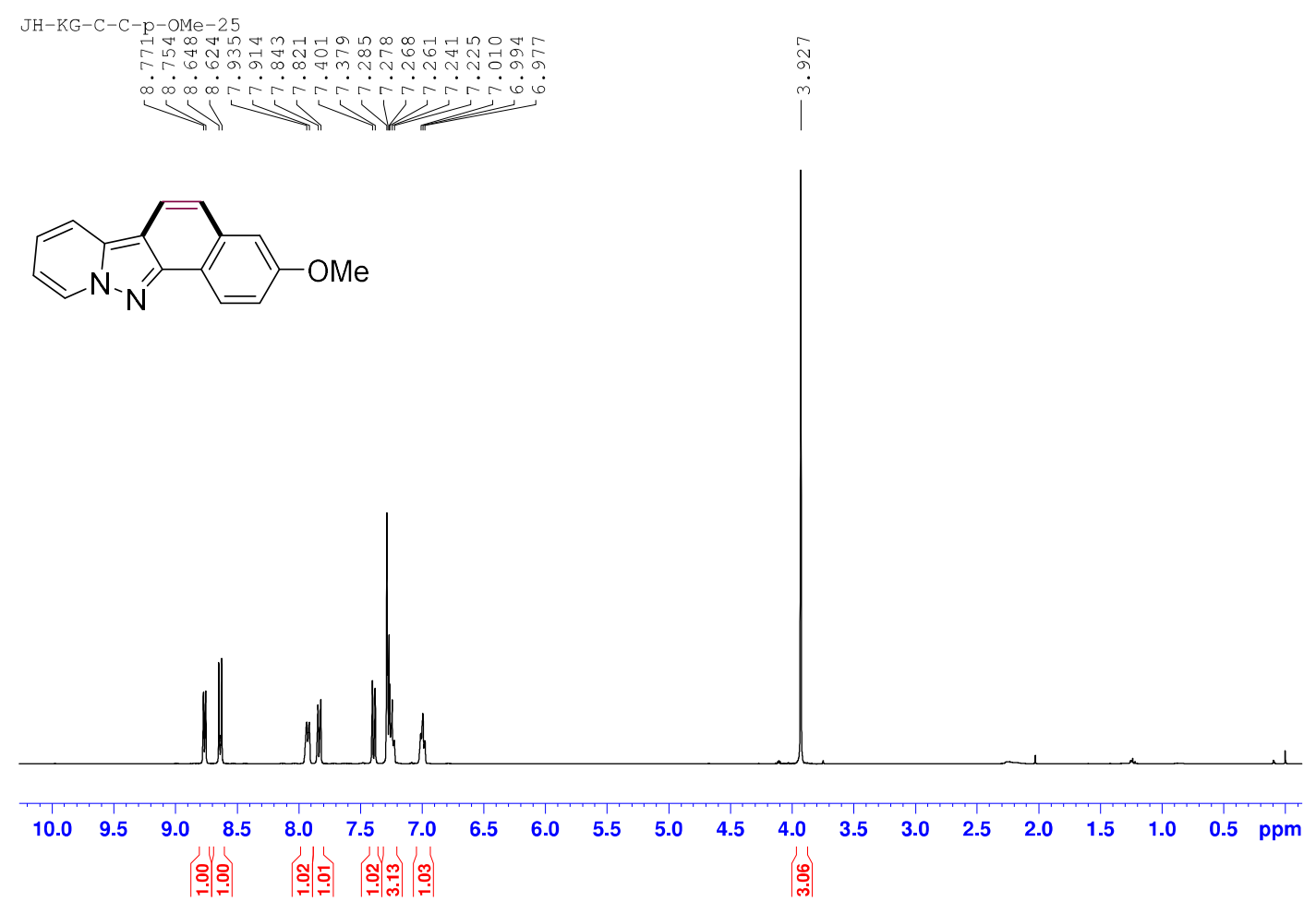

${ }^{13} \mathrm{C} \mathrm{NMR}\left(\mathrm{CDCl}_{3}, 100 \mathrm{MHz}\right)$ of $7 \mathrm{c}$

JH-KG-C-C-p-OMe-25

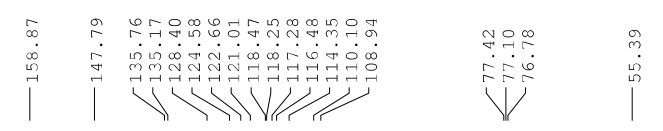

-OMe

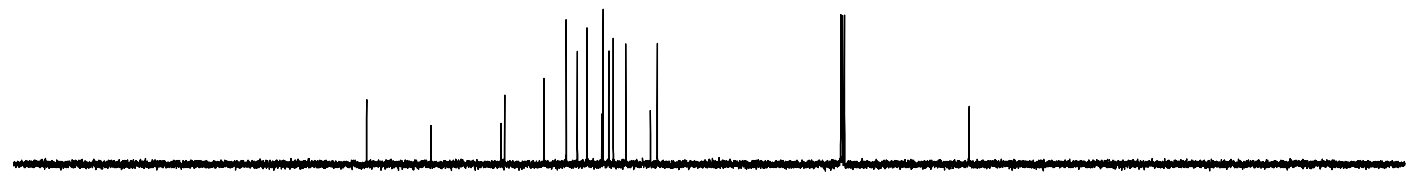

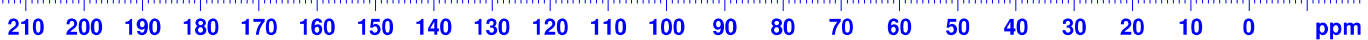


${ }^{1} \mathrm{H} \mathrm{NMR}\left(\mathrm{CDCl}_{3}, 400 \mathrm{MHz}\right)$ of 7d

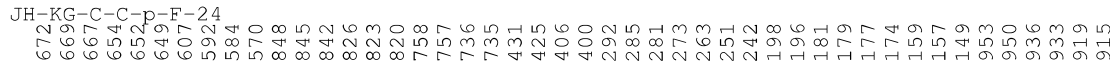

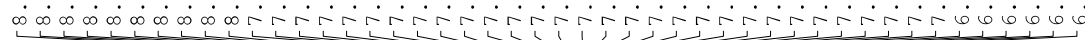<smiles>Fc1ccc2ccc3c(nn4ccccc34)c2c1</smiles>

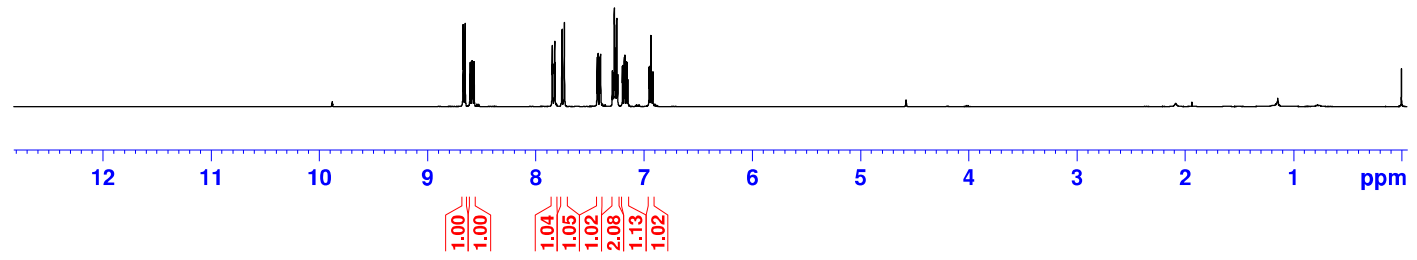

${ }^{13} \mathrm{C} \mathrm{NMR}\left(\mathrm{CDCl}_{3}, 100 \mathrm{MHz}\right)$ of $7 \mathbf{d}$

$\mathrm{JH}-\mathrm{KG}-\mathrm{C}-\mathrm{C}-\mathrm{p}-\mathrm{F}-24$

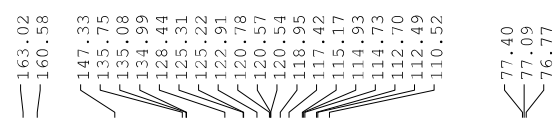

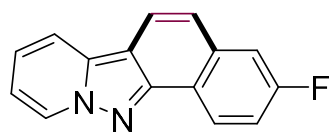

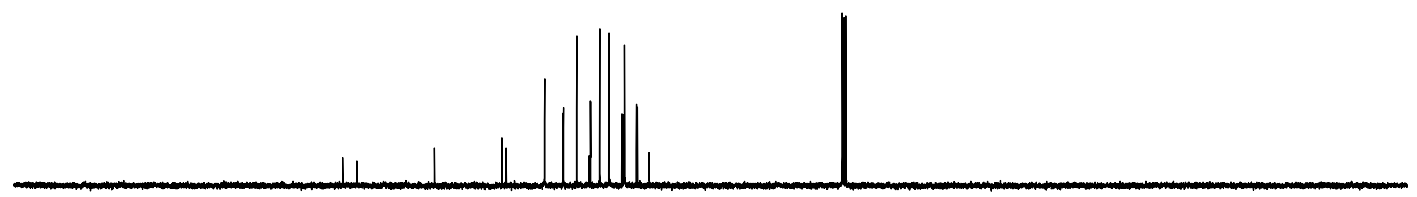

$\begin{array}{lllllllllllllllllllllll}210 & 200 & 190 & 180 & 170 & 160 & 150 & 140 & 130 & 120 & 110 & 100 & 90 & 80 & 70 & 60 & 50 & 40 & 30 & 20 & 10 & 0 & \mathrm{ppm}\end{array}$ 
${ }^{19} \mathrm{~F} \mathrm{NMR}\left(\mathrm{CDCl}_{3}, 376 \mathrm{MHz}\right)$ of $7 \mathbf{d}$

JH-KG-E19-7d<smiles>Fc1ccc2c(ccc3c2nn2ccccc32)c1</smiles>

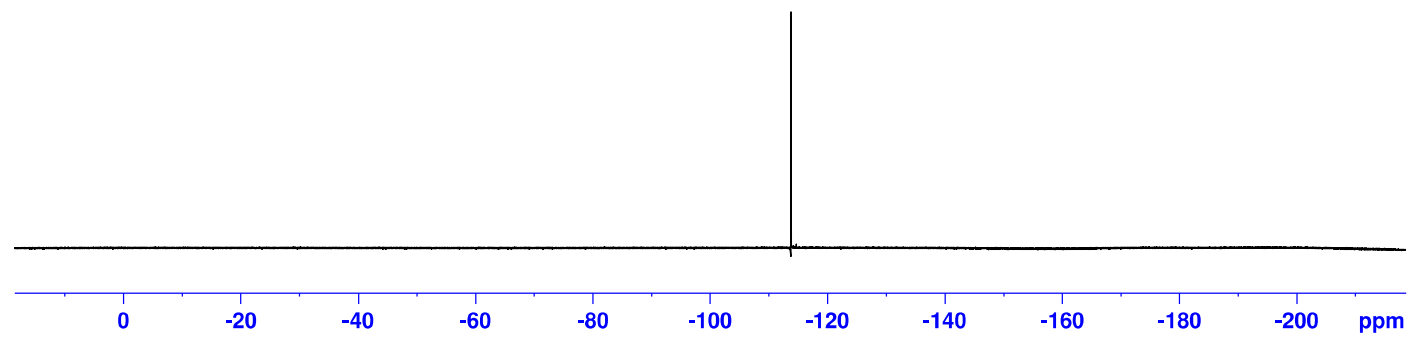




\section{Cartesian coordinates of the optimized structures}

Table S4. Summary of the calculated energies

$\begin{array}{cccc}\text { compd } & \text { onset } \lambda_{\text {abs }}\left(\mathrm{CHCl}_{3} \text { solution }\right) & E_{\mathrm{g}}\left(\mathrm{CHCl}_{3} \text { solution }\right) & \mathrm{HOMO}(\mathrm{DFT}) \\ \mathbf{3 a} & 400 \mathrm{~nm} & 3.10 \mathrm{eV} & -5.265 \mathrm{eV} \\ \mathbf{6 a} & 403 \mathrm{~nm} & 3.08 \mathrm{eV} & -5.258 \mathrm{eV} \\ \mathbf{7 a} & 384 \mathrm{~nm} & 3.23 \mathrm{eV} & -5.170 \mathrm{eV}\end{array}$

Table S5. Summary of the frequency calculation

\begin{tabular}{cccc} 
compd & \# of imaginary frequency & enthalpy [Hartree] & free energy [Hartree] \\
\hline 3a & 0 & -686.923020 & -686.972275 \\
$\mathbf{6 a}$ & 0 & -686.902386 & -686.951544 \\
$\mathbf{7 a}$ & 0 & -686.901710 & -686.950902
\end{tabular}

3a

\begin{tabular}{|c|c|c|c|}
\hline $\mathrm{C}$ & 1.5066 & 2.0626 & 0.0000 \\
\hline $\mathrm{C}$ & 2.2675 & 0.8455 & 0.0000 \\
\hline $\mathrm{C}$ & 1.6049 & -0.4239 & 0.0000 \\
\hline $\mathrm{C}$ & 0.1744 & -0.4150 & 0.0000 \\
\hline $\mathrm{C}$ & -0.5158 & 0.8108 & 0.0000 \\
\hline $\mathrm{C}$ & 0.1330 & 2.0652 & 0.0000 \\
\hline $\mathrm{H}$ & 2.0474 & 3.0053 & 0.0000 \\
\hline $\mathrm{H}$ & -0.4250 & 2.9972 & 0.0000 \\
\hline $\mathrm{C}$ & -1.8955 & -0.9523 & 0.0000 \\
\hline $\mathrm{C}$ & -3.1687 & -1.5734 & 0.0000 \\
\hline $\mathrm{C}$ & -4.3044 & -0.8025 & 0.0000 \\
\hline $\mathrm{C}$ & -4.2169 & 0.6210 & 0.0000 \\
\hline $\mathrm{C}$ & -2.9957 & 1.2319 & 0.0000 \\
\hline $\mathrm{H}$ & -3.2020 & -2.6570 & 0.0000 \\
\hline $\mathrm{H}$ & -5.2817 & -1.2751 & 0.0000 \\
\hline $\mathrm{H}$ & -5.1132 & 1.2308 & 0.0000 \\
\hline $\mathrm{H}$ & -2.8553 & 2.3064 & 0.0000 \\
\hline $\mathrm{C}$ & 2.3640 & -1.6143 & 0.0000 \\
\hline $\mathrm{C}$ & 3.7442 & -1.5613 & 0.0000 \\
\hline $\mathrm{H}$ & 4.3234 & -2.4809 & 0.0000 \\
\hline $\mathrm{H}$ & 1.8359 & -2.5630 & 0.0000 \\
\hline $\mathrm{N}$ & -0.6801 & -1.4845 & 0.0000 \\
\hline $\mathrm{N}$ & -1.8581 & 0.4653 & 0.0000 \\
\hline $\mathrm{C}$ & 3.6846 & 0.8604 & 0.0000 \\
\hline $\mathrm{C}$ & 4.4085 & -0.3154 & 0.0000 \\
\hline
\end{tabular}




\begin{tabular}{|c|c|c|c|}
\hline $\mathrm{H}$ & 4.1981 & 1.8195 & 0.0000 \\
\hline $\mathrm{H}$ & 5.4950 & -0.2835 & 0.0000 \\
\hline
\end{tabular}

$6 a$

\begin{tabular}{|c|c|c|c|}
\hline $\mathrm{C}$ & -1.5719 & 2.1039 & 0.0000 \\
\hline $\mathrm{C}$ & -2.2827 & 0.8566 & 0.0000 \\
\hline $\mathrm{C}$ & -1.5591 & -0.3654 & 0.0000 \\
\hline $\mathrm{C}$ & 0.5223 & 0.9092 & 0.0000 \\
\hline $\mathrm{C}$ & -0.2066 & 2.1258 & 0.0000 \\
\hline $\mathrm{H}$ & -2.1414 & 3.0286 & 0.0000 \\
\hline $\mathrm{H}$ & 0.3445 & 3.0608 & 0.0000 \\
\hline $\mathrm{C}$ & 1.8773 & -0.8826 & 0.0000 \\
\hline $\mathrm{C}$ & 3.0957 & -1.6047 & 0.0000 \\
\hline $\mathrm{C}$ & 4.2715 & -0.8860 & 0.0000 \\
\hline $\mathrm{C}$ & 4.2821 & 0.5381 & 0.0000 \\
\hline $\mathrm{C}$ & 3.1070 & 1.2608 & 0.0000 \\
\hline $\mathrm{H}$ & 3.0867 & -2.6901 & 0.0000 \\
\hline $\mathrm{H}$ & 5.2211 & -1.4150 & 0.0000 \\
\hline $\mathrm{H}$ & 5.2361 & 1.0579 & 0.0000 \\
\hline $\mathrm{H}$ & 3.1215 & 2.3476 & 0.0000 \\
\hline $\mathrm{C}$ & -2.2178 & -1.6052 & 0.0000 \\
\hline $\mathrm{C}$ & -3.6022 & -1.6344 & 0.0000 \\
\hline $\mathrm{H}$ & -4.1174 & -2.5906 & 0.0000 \\
\hline $\mathrm{H}$ & -1.6236 & -2.5109 & 0.0000 \\
\hline $\mathrm{N}$ & 0.6222 & -1.3890 & 0.0000 \\
\hline $\mathrm{C}$ & -3.6943 & 0.7821 & 0.0000 \\
\hline $\mathrm{C}$ & -4.3450 & -0.4380 & 0.0000 \\
\hline $\mathrm{H}$ & -4.2624 & 1.7089 & 0.0000 \\
\hline $\mathrm{H}$ & -5.4305 & -0.4748 & 0.0000 \\
\hline $\mathrm{C}$ & 1.8872 & 0.5498 & 0.0000 \\
\hline $\mathrm{N}$ & -0.1674 & -0.2942 & 0.0000 \\
\hline
\end{tabular}

$7 a$

\begin{tabular}{|c|c|c|c|}
\hline $\mathrm{C}$ & -1.5732 & 2.0868 & 0.0000 \\
\hline $\mathrm{C}$ & -2.2987 & 0.8408 & 0.0000 \\
\hline $\mathrm{C}$ & -1.5997 & -0.4044 & 0.0000 \\
\hline $\mathrm{C}$ & -0.1625 & -0.3448 & 0.0000 \\
\hline $\mathrm{C}$ & 0.5160 & 0.9043 & 0.0000 \\
\hline
\end{tabular}




\begin{tabular}{|c|c|c|c|}
\hline $\mathrm{C}$ & -0.2070 & 2.1304 & 0.0000 \\
\hline $\mathrm{H}$ & -2.1479 & 3.0095 & 0.0000 \\
\hline $\mathrm{H}$ & 0.3177 & 3.0821 & 0.0000 \\
\hline $\mathrm{C}$ & 3.0693 & -1.5504 & 0.0000 \\
\hline $\mathrm{C}$ & 4.2659 & -0.8840 & 0.0000 \\
\hline $\mathrm{C}$ & 4.2952 & 0.5359 & 0.0000 \\
\hline $\mathrm{C}$ & 3.1168 & 1.2495 & 0.0000 \\
\hline $\mathrm{H}$ & 2.9489 & -2.6260 & 0.0000 \\
\hline $\mathrm{H}$ & 5.1859 & -1.4579 & 0.0000 \\
\hline $\mathrm{H}$ & 5.2483 & 1.0551 & 0.0000 \\
\hline $\mathrm{H}$ & 3.1141 & 2.3348 & 0.0000 \\
\hline $\mathrm{C}$ & -2.3192 & -1.6163 & 0.0000 \\
\hline $\mathrm{C}$ & -3.7029 & -1.6087 & 0.0000 \\
\hline $\mathrm{H}$ & -4.2516 & -2.5467 & 0.0000 \\
\hline $\mathrm{H}$ & -1.7657 & -2.5503 & 0.0000 \\
\hline $\mathrm{N}$ & 0.6787 & -1.4013 & 0.0000 \\
\hline $\mathrm{C}$ & -3.7130 & 0.8126 & 0.0000 \\
\hline $\mathrm{C}$ & -4.4031 & -0.3861 & 0.0000 \\
\hline $\mathrm{H}$ & -4.2553 & 1.7554 & 0.0000 \\
\hline $\mathrm{H}$ & -5.4899 & -0.3858 & 0.0000 \\
\hline $\mathrm{N}$ & 1.9048 & -0.8356 & 0.0000 \\
\hline $\mathrm{C}$ & 1.8846 & 0.5656 & 0.0000 \\
\hline
\end{tabular}




\section{References}

${ }^{1}$ (a) Bagdi, A. K.; Rahman, M.; Santra, S.; Majee, A.; Hajra, A. Adv. Synth. Catal. 2013, 355, 1741. (b) Dey, A.; Hajra, A. J. Org. Chem. 2019, 84, 14904. (c) Ding, S.; Yan, Y.; Jiao, N. Chem. Commun. 2013, 49, 4250. (d) Redon, S.; Kosso, A. R. O.; Broggi, J.; Vanelle, P. Tetrahedron Lett. 2017, 58, 2771.

${ }^{2}$ (a) Stuart, D. R.; Alsabeh, P.; Kuhn, M.; Fagnou, K. J. Am. Chem. Soc. 2010, 132, 18326. (b) Esqueda, A. C.; Conejero, S.; Maya, M.; Carmona, E. Organometallics 2009, $28,45$.

${ }^{3}$ Mosby, W. L.; Boyle, R. J. J. Org. Chem. 1959, 24, 374.

${ }^{4}$ Zhao, J.; Wu, C.; Li, P.; Ai, W.; Chen, H.; Wang, C.; Larock, R. C.; Shi, F. J. Org. Chem. 2011, 76, 6837.

${ }^{5}$ Reddy, Y. P.; Reddy, K. K. Indian J. Chem., Sect B, 1988, 27, 563.

${ }^{6}$ Reported as a mixture of isomers: Zhao, J.; Li, P.; Wu, C.; Chen, H.; Ai, W.; Sun, R.; Ren, H.; Larock, R. C.; Shi, F. Org. Biomol. Chem. 2012, 10, 1922.

${ }^{7}$ Sheldrick, G. M. Acta Crystallogr. Sect. A 2008, 64, 112 ..

${ }^{8}$ Farrugia, L. J. J. Appl. Cryst. 2012, 45, 849. 